Elsevier Editorial System(tm) for Progress in Retinal and Eye Research Manuscript Draft

Manuscript Number: JPRR-D-14-00016R1

Title: Stem cells as source for retinal pigment epithelium transplantation

Article Type: Article for JPRR

Keywords: retinal stem cells, retinal neurospheres, RPE65, LRAT, bestrophin 1, beta5-integrin, 0A1, CRALBP, MITF

Corresponding Author: Prof. Valeria Marigo, $\mathrm{PhD}$

Corresponding Author's Institution: University of Modena and Reggio Emilia

First Author: Evelina Bertolotti, PhD

Order of Authors: Evelina Bertolotti, PhD; Alberto Neri, MD; Monica Camparini, MD; Claudio Macaluso, MD; Valeria Marigo, PhD

Abstract: Inherited maculopathies, age related macular degeneration and some forms of retinitis pigmentosa are associated with impaired function or loss of the retinal pigment epithelium (RPE).

Among potential treatments, transplantation approaches are particularly promising. The arrangement of RPE cells in a well-defined tissue layer makes the RPE amenable to cell or tissue sheet transplantation. Different cell sources have been suggested for RPE transplantation but the development of a clinical protocol faces several obstacles. The source should provide a sufficient number of cells to at least recover the macula area. Secondly, cells should be plastic enough to be able to integrate in the host tissue. Tissue sheets should be considered as well, but the substrate on which RPE cells are cultured needs to be carefully evaluated. Immunogenicity can also be an obstacle for effective transplantation as well as tumorigenicity of not fully differentiated cells. Finally, ethical concerns may represent drawbacks when embryo-derived cells are proposed for RPE transplantation. Here we discuss different cell sources that became available in recent years and their different properties. We also present data on a new source of human RPE. We provide a protocol for RPE differentiation of retinal stem cells derived from adult ciliary bodies of post-mortem donors. We show molecular characterization of the in vitro differentiated RPE tissue and demonstrate its functionality based on a phagocytosis assay. This new source may provide tissue for allogenic transplantation based on best matches through histocompatibility testing. 


\section{Stem cells as source for retinal pigment epithelium transplantation}

Evelina Bertolotti ${ }^{1}$, Alberto Neri ${ }^{2}$, Monica Camparini ${ }^{2}$, Claudio Macaluso ${ }^{2}$, Valeria Marigo ${ }^{1, *}$

${ }^{1}$ Department of Life Sciences, University of Modena and Reggio Emilia, Modena, Italy

${ }^{2}$ Ophthalmology, S.Bi.Bi.T. Department, University of Parma, Parma, Italy

"Corresponding Author: Valeria Marigo, Department of Life Sciences, University of Modena and Reggio Emilia, via Campi 287, 41125 Modena, Italy; phone: +390592055392; fax: +390592055410; email: valeria.marigo@unimore.it 


\section{Abstract}

Inherited maculopathies, age related macular degeneration and some forms of retinitis pigmentosa are associated with impaired function or loss of the retinal pigment epithelium (RPE). Among potential treatments, transplantation approaches are particularly promising. The arrangement of RPE cells in a well-defined tissue layer makes the RPE amenable to cell or tissue sheet transplantation. Different cell sources have been suggested for RPE transplantation but the development of a clinical protocol faces several obstacles. The source should provide a sufficient number of cells to at least recover the macula area. Secondly, cells should be plastic enough to be able to integrate in the host tissue. Tissue sheets should be considered as well, but the substrate on which RPE cells are cultured needs to be carefully evaluated. Immunogenicity can also be an obstacle for effective transplantation as well as tumorigenicity of not fully differentiated cells. Finally, ethical concerns may represent drawbacks when embryo-derived cells are proposed for RPE transplantation. Here we discuss different cell sources that became available in recent years and their different properties. We also present data on a new source of human RPE. We provide a protocol for RPE differentiation of retinal stem cells derived from adult ciliary bodies of post-mortem donors. We show molecular characterization of the in vitro differentiated RPE tissue and demonstrate its functionality based on a phagocytosis assay. This new source may provide tissue for allogenic transplantation based on best matches through histocompatibility testing. 


\section{Contents}

1 Introduction

2 Molecular and functional characteristics of the RPE and related diseases

2.1 Molecular and structural characteristics of RPE cells

2.2 RPE function in photoreceptor outer segment turnover

2.3 Role of the RPE in the visual cycle

2.4 Polarization of the RPE

2.5 Pigmentation of the RPE

2.6 RPE in retinal diseases

3 Generating RPE in vitro

3.1 Embryonic stem cells and induced pluripotent stem cells as sources of RPE

3.2 Adult RPE as a source of RPE

3.3 Retinal neurospheres (RNS) as source of RPE

4 Generation of human RNS from post-mortem donations

4.1 Tissue collection and dissociation

4.2 RNS culture

5 In vitro differentiation of RNS into human RPE

5.1 Differentiation of RPE sheets from RNS 
5.2 Molecular characterization of the in vitro generated RPE

5.3 Phagocytosis activity of RPE cells in the newly formed sheets of tissue

6 Future directions

Acknowledgments

References 


\section{Stem cells as source for retinal pigment epithelium transplantation}

Evelina Bertolotti ${ }^{1}$, Alberto Neri ${ }^{2}$, Monica Camparini ${ }^{2}$, Claudio Macaluso ${ }^{2}$, Valeria Marigo ${ }^{1, *}$

${ }^{1}$ Department of Life Sciences, University of Modena and Reggio Emilia, Modena, Italy

${ }^{2}$ Ophthalmology, S.Bi.Bi.T. Department, University of Parma, Parma, Italy

"Corresponding Author: Valeria Marigo, Department of Life Sciences, University of Modena and Reggio Emilia, via Campi 287, 41125 Modena, Italy; phone: +390592055392; fax: +390592055410; email: valeria.marigo@unimore.it 


\section{Abstract}

Inherited maculopathies, age related macular degeneration and some forms of retinitis pigmentosa are associated with impaired function or loss of the retinal pigment epithelium (RPE). Among potential treatments, transplantation approaches are particularly promising. The arrangement of RPE cells in a well-defined tissue layer makes the RPE amenable to cell or tissue sheet transplantation. Different cell sources have been suggested for RPE transplantation but the development of a clinical protocol faces several obstacles. The source should provide a sufficient number of cells to at least recover the macula area. Secondly, cells should be plastic enough to be able to integrate in the host tissue. Tissue sheets should be considered as well, but the substrate on which RPE cells are cultured needs to be carefully evaluated. Immunogenicity can also be an obstacle for effective transplantation as well as tumorigenicity of not fully differentiated cells. Finally, ethical concerns may represent drawbacks when embryo-derived cells are proposed for RPE transplantation. Here we discuss different cell sources that became available in recent years and their different properties. We also present data on a new source of human RPE. We provide a protocol for RPE differentiation of retinal stem cells derived from adult ciliary bodies of post-mortem donors. We show molecular characterization of the in vitro differentiated RPE tissue and demonstrate its functionality based on a phagocytosis assay. This new source may provide tissue for allogenic transplantation based on best matches through histocompatibility testing. 


\section{Contents}

1 Introduction

2 Molecular and functional characteristics of the RPE and related diseases

2.1 Molecular and structural characteristics of RPE cells

2.2 RPE function in photoreceptor outer segment turnover

2.3 Role of the RPE in the visual cycle

2.4 Polarization of the RPE

2.5 Pigmentation of the RPE

2.6 RPE in retinal diseases

3 Generating RPE in vitro

3.1 Embryonic stem cells and induced pluripotent stem cells as sources of RPE

3.2 Adult RPE as a source of RPE

3.3 Retinal neurospheres (RNS) as source of RPE

4 Generation of human RNS from post-mortem donations

4.1 Tissue collection and dissociation

4.2 RNS culture

5 In vitro differentiation of RNS into human RPE

5.1 Differentiation of RPE sheets from RNS 
5.2 Molecular characterization of the in vitro generated RPE

5.3 Phagocytosis activity of RPE cells in the newly formed sheets of tissue

6 Future directions

Acknowledgments

References 


\section{Introduction}

The retinal pigment epithelium (RPE) is a highly specialized epithelium with a neuroectodermal embryonic origin like the retina. While the retina was first described by Galen in the second century A.D., discovery of the RPE required the use of the first rudimentary microscopes in the $18^{\text {th }}$ century and was described by Carlo Mondini of Bologna in his "Commentationes Bononienses" (1790) as "a real membrane formed by innumerable globules which makes an excessively delicate network" (Marmor and Wolfensberger, 1998). The histology of the RPE was then elucidated at the end of the $19^{\text {th }}$ century and further characterized in more recent times.

The eyes derive from two evaginations of the forebrain that generate the optic vesicles connected to the brain by the optic stalks. The optic vesicles then invaginate to form the optic cups with the outer layer destined to become the RPE. The outer stratum is a monolayer of cells that differentiate during embryonic/fetal development and is characterized by pigmentation, which appears during the $5^{\text {th }}$ week of human embryogenesis. RPE differentiation is induced by several factors including the signaling molecule Activin, a member of the TGF $\beta$ family, which is secreted by adjacent mesenchymal cells. These signals induce expression of transcription factors, such as microphthalmia-associated transcription factor (MITF), orthodenticle homolog 2 (OTX2) and paired box 6 (PAX6), that are essential for RPE specification and to drive expression of proteins necessary for the distinguishing functions of the RPE (Bharti et al., 2012; Fuhrmann et al., 2000; Housset et al., 2013). The fully differentiated RPE consists of a polarized monolayer of pigmented cells with a basal side adherent to the Bruch's membrane, which separates the RPE from the choroid, and an apical membrane facing the photoreceptor cells. 
In this paper we summarize molecular and functional characteristics of the RPE tissue since the characterization of these features is required when RPE is generated in vitro. We also discuss RPE impairment and diseases that will be amenable to cell replacement strategies. We review several stem cell sources to produce RPE in vitro. Finally, we present a new protocol for the differentiation of adult human retinal stem cells into RPE sheets.

\section{Molecular and functional characteristics of the RPE and related diseases}

\subsection{Molecular and structural characteristics of RPE cells}

RPE cells are characterized by asymmetrical distribution of molecules at the cell surface and compartmentalization of the organelles in the cytoplasm (Figure 1). Morphological differences between apical and basal membranes are infoldings at the basal membrane and microvilli at the apical side. The apical projections not only increase the apical cell surface but also envelop photoreceptor cell outer segments (POS) and mediate the turnover of the tip of the photoreceptors cells through phagocytosis. Organelles and cytoskeleton filaments are localized differently along the apicobasal axis. The nucleus and mitochondria are found at the basal side of RPE cells and pigmented melanosomes are transferred to the apical zone where they orient parallel to the incoming light. During differentiation, adherens junctions form among adjacent cells and are mediated by cadherins, namely cadherin 2 (N-cadherin) and cadherin 3 (P-cadherin) (Burke et al., 1999; Lagunowich and Grunwald, 1989; Murphy-Erdosh et al., 1994). Formation of adherens junctions is followed by the formation of circumferential bundles of actin filaments to build zonula adherens junctions (Nabi et al., 1993; Owaribe and Masuda, 1982; Williams and Rizzolo, 1997). This remodeling affects the cytoskeleton leading to the 
development of distinct apical, lateral and basal membrane territories hosting specific proteins. Gap-junctions in the lateral membrane are transmembrane channels that mediate cell-cell communication between adjacent RPE cells. Connexin 43 is one of the components of the gap-junctions in the RPE tissue and was reported to play a role in differentiation of RPE cells (Kojima et al., 2008). The apical and basolateral domains are segregated by tight junctions and different proteins and lipids are specifically sorted to the two compartments. For example, the basolateral side of the RPE cell harbors the chloride channel bestrophin 1 (Marmorstein et al., 2000; Sun et al., 2002). $\mathrm{Na}^{+} / \mathrm{K}^{+}$ATPase can be found preferentially at the apical plasma membrane of RPE cells, rather than at the basolateral membrane as in most epithelial cells (Caldwell and McLaughlin, 1984). In fact, RPE cells exhibit a reversed polarity compared to other epithelial cells and the specific localization of the $\mathrm{Na}^{+} / \mathrm{K}^{+}$ATPase appears to be directed by the preferential expression of $\mathrm{N}$-cadherin compared to E-cadherin (Burke et al., 2000). Members of the ezrin/moesin family of actin-binding proteins are localized at the apical plasma membrane in RPE cells (Höfer and Drenckhahn, 1993) and apical microvilli are characterized by the expression of

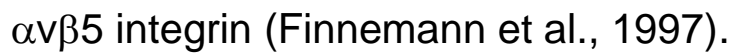

\subsection{RPE function in photoreceptor outer segment turnover}

The RPE serves several functions that are essential for vision and survival of retinal neurons and several eye diseases are caused by impairments of these functions. One of the most important functions of the RPE is the removal and degradation of the tips of POS (Figure 2A). Phagocytosis of POS distal tips follows a circadian rhythm and is triggered by light. The direct role of the RPE in phagocytosis was demonstrated more than 40 years ago by radioactive amino acid delivery as a pulse and detection of radioactive phagosomes inside the RPE (Young and Bok, 1969). Young and Bok also demonstrated 
that RPE cells actively participate in the disposal of POS distal tips because radioactive phagocytized POS were then eliminated from RPE cells. In the renewal process POS are newly built at the base of the outer segment while the tip of the outer segment contains the highest concentration of old and photo-damaged proteins and lipids that need to be removed. Through coordinated POS tip shedding and new POS production a constant length of the POS is maintained. Diurnal binding of POS to the RPE is mediated by $\alpha \mathrm{V} \beta 5$ integrin through the secreted glycoprotein milk fat globule-EGF 8 (MFG-E8) that acts as a ligand mediating the binding of POS to $\alpha \mathrm{v} \beta 5$ integrin via its RGD motif (Finnemann et al., 1997; Nandrot and Finnemann, 2006; Nandrot et al., 2007, 2004). The scavenger receptor CD36, a transmembrane glycoprotein in the RPE, acts in POS uptake through detection of oxidized phospholipids but not in initial binding of POS (Ryeom et al., 1996; Sun et al., 2006). CD36 is also involved in the clearance of oxidized low-density lipoprotein subretinal deposits (Picard et al., 2010). Nevertheless, $\alpha \mathrm{v} \beta 5$ integrin is not necessary for POS internalization. Internalization of POS requires c-mer proto-oncogene tyrosine kinase (MERTK), a receptor activated upon tyrosine phosphorylation by focal adhesion kinase (FAK), a downstream effector of $\alpha v \beta 5$ integrin (D'Cruz et al., 2000; Vollrath et al., 2001). MERTK ligands, such as growth arrest specific protein 6 (GAS6), Tubby and protein S, also play important roles in POS phagocytosis (Caberoy et al., 2010; Finnemann, 2003; Hall et al., 2005, 2001). Finally, cathepsin D, a lysosomal enzyme, participates to the degradation of internalized POS (Rakoczy et al., 1997). Impaired phagocytic function of the RPE is associated with subretinal accumulation of POS and rapid degeneration of photoreceptors as in Retinitis Pigmentosa (RP) caused by mutation in MERTK (D'Cruz et al., 2000; Gal et al., 2000; Vollrath et al., 2001). Murine models lacking $\alpha \mathrm{v} \beta 5$ integrin or CD36 also display compromised phagocytosis leading to blindness (Houssier et al., 2008; Nandrot et al., 2004). 


\subsection{Role of the RPE in the visual cycle}

Another fundamental function of the RPE is retinoid recycling (Figure 2B). Absorption of a photon of light by rhodopsin causes isomerisation of the chromophore from 11-cis retinal to all-trans-retinal, which is released from opsin. In order to reconstitute rhodopsin, alltrans retinal must be converted back to 11 -cis retinal through a multistep pathway called visual cycle. The visual cycle begins in the photoreceptor outer segment discs where the ATP-binding cassette subfamily A member 4 (ABCA4) transfers all-trans retinal from the intradiscal membrane surface to the cytoplasmic membrane surface (Sullivan, 2009). The all-trans-retinal is then reduced to all-trans retinol by retinol dehydrogenases (RDH8 and RDH12) (Belyaeva et al., 2005; Chen et al., 2012). All-trans retinol is transported through the interphotoreceptor matrix to the RPE by the interphotoreceptor retinoid-binding protein (IRBP) (Okajima et al., 1989). All-trans retinol is also supplied to the RPE by the choroidal vasculature and enters the RPE cells in a receptor-mediated process involving recognition of a serum retinol-binding protein/transthyretin (RBP/TTR) complex by the STRA6 receptor (Kawaguchi et al., 2007; Pfeffer et al., 1986). Within the RPE, all-trans retinol is bound to the cellular retinaldehyde-binding protein (CRALBP) encoded by the RLBP1 gene (Saari et al., 1982). The conversion of all-trans retinol to 11-cis retinal requires an enzymatic cascade involving at least three enzymes associated with the RPE smooth endoplasmic reticulum. The reaction starts with esterification of all-trans retinol to all-trans retinyl esters by the enzyme lecithin:retinol acyltransferase (LRAT) (Ruiz et al., 1999; Saari et al., 1993). Then an isomerohydrolase, called retinal pigment epithelium-specific protein $65 \mathrm{kDa}$ (RPE65), catalyses the concerted hydrolysis of all-trans retinyl ester and the isomerization to 11-cis retinol (Jin et al., 2005; Moiseyev et al., 2005; Redmond et al., 2005). 11-cis retinol dehydrogenase (RDH5) converts 11-cis retinol to the final product 11-cis retinal 
(Driessen et al., 1995; Simon et al., 1995). 11-cis retinal then exits the RPE and combines with the opsin protein in photoreceptor cells to form the visual pigment. This step is mediated by IRBP with its capacity to remove 11 - cis retinal from membranes (Carlson and Bok, 1999). In many human retinal dystrophies the visual cycle is disturbed resulting in the inability to either produce an adequate supply of 11-cis retinal or a failure to remove intermediate retinoid products.

\subsection{Polarization of the RPE}

Photoreceptors are tightly interdigitated with RPE microvilli and this is required to maintain the retina in a fixed plane necessary for the optics, as well as for exchange of nutrients and oxygen from the choriocapillaris to the photoreceptors. This exchange is strictly regulated by the RPE (Figure $2 \mathrm{C}$ ). The tight nature of the subretinal space between RPE and retina necessitates fluids to be kept out. Under physiological conditions aquaporins, water channel proteins, allow water transport apical to basal through RPE cells at a rate of 2 to $18 \mu \mathrm{L} / \mathrm{cm}^{2}$ per hour (Stamer et al., 2003) and in cases of RPE detachment a transport of fluid could be confirmed in human RPE (Chihara and Nao-i, 1985). Tight junctions among RPE cells provide a barrier against the passage of substances from the fenestrated choroidal capillaries to the retina and generate the external blood-retinal barrier. Electrical parameters can be recorded with RPE tissue mounted in an Ussing chamber and the difference between resting potentials of apical and basolateral membranes in the RPE generates a transepithelial potential that is linked to the different types and distribution of ion channels and other transporters (Gallemore et al., 1993). A specific and regulated traffic of ions either in the retina-to-choroid or choroid-to-retina directions relies on the RPE. The RPE actively transports $\mathrm{Cl}^{-}$and $\mathrm{HCO}_{3}{ }^{-}$from the retina to the choroid and $\mathrm{Na}^{+}$in the opposite direction (Miller and Edelman, 1990). $\mathrm{Cl}^{-}$enters through an apical membrane 
$\mathrm{Na}^{+}-\mathrm{K}^{+}-2 \mathrm{Cl}^{-}$co-transporter and is extruded at the basolateral membrane. The basolateral membrane is characterized by the presence of several chloride channels including cystic fibrosis transmembrane conductance regulator (CFTR) and bestrophin 1 (Weng et al., 2002). Bestrophin 1 is a homo-oligomeric integral membrane protein forming anion channels (Marmorstein et al., 2000; Stanton et al., 2006). Bestrophin 1 transports $\mathrm{Cl}^{-}$in a $\mathrm{Ca}^{2+}$ dependent manner but may also have intracellular functions not well characterized yet (Qu and Hartzell, 2008; Strauss et al., 2014). Mutations in the BEST1 gene encoding for bestrophin 1 are linked to Best Vitelliform Macular Dystrophy (Marquardt et al., 1998; Petrukhin et al., 1998). Ion channels in RPE cells are important to buffer ion changes in response to light stimuli because light induces a decrease of $\mathrm{K}^{+}$ion concentration in the subretinal space that causes hyperpolarization of the apical membrane of the RPE and activation of inward rectifier $\mathrm{K}^{+}$channels. The $\mathrm{K}^{+}$conductance is electrically coupled to the basolateral $\mathrm{Cl}^{-}$conductance and this coupling is important for buffering the chemical composition of the subretinal space (Bialek and Miller, 1994). The RPE also secrets trophic factors (Figure 2C) such as the pigment epithelium-derived factor (PEDF), a protein implicated in the survival and normal function of the retina (Barnstable and Tombran-Tink, 2004). PEDF is found in the healthy human eye and its levels are altered in eyes affected by retinal degenerative processes (Holekamp et al., 2002; Mohan et al., 2012; Ogata et al., 2004, 2002; Wang et al., 2013). The basal side of the RPE secretes the vascular endothelial growth factor (VEGF-A), required to maintain the choroidal circulation (Marneros et al., 2005; Saint-Geniez et al., 2009). VEGF-A is target of therapies for wet Age-related Macular Degeneration (AMD) (Kaiser, 2013). 


\subsection{Pigmentation of the RPE}

Melanogenesis in the RPE is fundamental for sight as reduced pigmentation causes vision impairment. Melanin is synthesized inside intracellular organelles called melanosomes. Melanosome biogenesis requires sequential maturation stages involving morphological and molecular changes (Figure 2D). Before melanin is deposited, intraluminal fibrillar sheets composed of the premelanosomal protein 17 (PMEL17) assemble inside melanosomes (Berson et al., 2001). Melanin biosynthesis enzymes, i.e. tyrosinase, tyrosinase-related protein 1 and Dopachrome tautomerase, are then delivered to the developing organelles and are necessary for the deposition of the black pigment (Raposo and Marks, 2007). Melanosome organellogenesis requires coordinated trafficking of proteins that involves adaptor-protein complexes (AP-1 and AP-3) (Dell'Angelica, 2009). Other proteins residing on the melanosomes are the P-protein (pink-eyed dilution homolog protein, OCA2), membrane-associated transport protein (MATP, OCA4) and the melanosome-specific G-protein coupled receptor called ocular albinism type 1 (GPR143/OA1). All these proteins are linked to different forms of albinism (Bassi et al., 1995; Brilliant, 2001; Newton et al., 2001; Oetting and King, 1994). The fully pigmented and mature melanosomes are stored within the RPE and contain black eumelanin. Two shapes can be observed in melanosomes: ellipsoid granules $(1 \mu \mathrm{m}$ in diameter and 2-3 $\mu \mathrm{m}$ in length) are primarily located at the apical portion and spherical granules reside in the mid-portion of the cell. Melanosomes redistribute to the apical processes of the RPE after light onset and this movement is mediated by Rab27a, melanophilin, and myosin Va (Futter et al., 2004). Melanin contributes to vision by preventing light reflection in the fundus and by protecting photoreceptors from an excess of dispersed light. Pigment granules are important not only for absorption of light but they also protect from oxidative stress and are involved in the binding of zinc and drugs (Schraermeyer and Heimann, 
1999; Ugarte and Osborne, 2014). Pigmentation in the RPE also influences ganglion cell projections and fovea development but the molecular mechanisms have not been well characterized yet.

\subsection{RPE in retinal diseases}

The RPE plays important roles in vision: absorption of stray light, formation of the bloodretinal barrier, regeneration of visual pigments and phagocytosis of the tip of POS (Strauss, 2005). Several retinal diseases are caused by loss or failing of one of these functions.

Albinism represents a group of genetic abnormalities due to defects in melanogenesis in the RPE. All albino patients have decreased visual acuity due to fovea hypoplasia and loss of stereoscopic vision due to the misrouting of the optic tracts (Harvey et al., 2006; Summers, 2009). During development, embryonic ganglion cell axons must find their way out of the retina into the optic nerve and extend along the optic tract to reach targets in the central nervous system. In the optic chiasm retinal axons segregate to pass into the optic tracts on either the same side (ipsilateral) or the opposite side of the brain (contralateral). The albino visual pathway is abnormal because of a reduction in the number of ipsilateral projecting ganglion cells. The molecular mechanisms regulating optic nerve formation and fovea development have not been completely elucidated and it is still not well understood why RPE pigmentation is necessary for these developmental processes (McAllister et al., 2010; Rachel et al., 2002; Rebsam et al., 2012). Albinism is not always associated to reduced melanin synthesis but can also be due to reduced number of melanosomes that likewise results in reduced pigmentation. In fact, mutations in the OA1 gene, causing ocular albinism type 1, affect melanosome biogenesis leading to decreased melanosome number and formation of aberrant organelles (Cortese et al., 2005; Giordano et al., 2009). 
As discussed above, a key role of the RPE in maintaining a healthy and functional retina resides in its tight association with photoreceptor cells. Any disruption of the photoreceptor-RPE complex may lead to various degrees of loss of visual function, depending not only on the biological severity of the disease process, but also on the region of the retina that is primarily affected. Several inherited and degenerative diseases, such as RP, inherited maculopathies (e.g. Stargardt Disease (STGD), Vitelliform Macular Distrophy (VMD)) and the dry form of age related macular degeneration (AMD), are associated with impaired RPE functions or loss of the photoreceptor-RPE complex.

STGD is the most common form of juvenile macular dystrophy leading to severe central vision loss. Autosomal recessive STGD is caused by mutations in the $A B C A 4$ gene that is also linked to other retinal degeneration phenotypes (Klevering et al., 2005). Impaired function of $\mathrm{ABCA} 4$ results in accumulation of toxic all-trans retinal derivatives in the photoreceptor outer segments, and following phagocytosis by RPE cells, all-trans retinal is converted to N-retinylidene-N-retinylethanolamine (A2E) and related bisretinoids that are the major components of lipofuscin. Rupture of lipofuscin-filled RPE cells leads to the end stage of the disease with loss of RPE and photoreceptors. The exact sequence of cell degeneration leading to photoreceptor and RPE atrophy in STGD remains controversial, with recent evidences of early photoreceptor anomalies (Gomes et al., 2009; Ritter et al., 2013) adding to the consolidated hypothesis that RPE damage occurs initially, with secondary photoreceptor degeneration (Eagle et al., 1980; Steinmetz et al., 1991). Nevertheless, it is interesting to note that mutations in a gene expressed in photoreceptors may lead to substantial impairment of RPE cells. Hence, we should be cautious in defining a priori the therapeutic potential of a given cell therapy based solely on the gene defect location, and improving our knowledge on the details of cell degeneration in different 
stages of a disease may become a critical element in deciding whether and when to initiate cell therapy, i.e. in defining the indications for a novel treatment.

The majority of the known mutations causing RP are associated with genes expressed in rod photoreceptors, however also genes specifically expressed in RPE, such as genes encoding for visual cycle enzymes (LRAT, RPE65, RDH5), can cause RP. Progressive degeneration in RP first leads to rod photoreceptor loss but subsequently affects also cones as well as the RPE with the formation of pigment depositions in the retina visible with fundus examination, hence the term "pigmentosa" for this family of retinal dystrophies (Koenekoop, 2009; Sancho-Pelluz et al., 2008; Wright et al., 2010).

No cure has been found yet for treating retinal degeneration, but several strategies are achieving initial results. These approaches can be divided into two broad groups: (1) those aiming at restoring health and function of surviving cells through gene supplementation (Bainbridge et al., 2008; Cideciyan et al., 2008; Cremers et al., 2002; Hauswirth et al., 2008; Maguire et al., 2008; Smith et al., 2009) or by treatments with neuroprotective molecules to slow the degeneration process (Frasson et al., 1999; Hamel, 2006; Léveillard and Sahel, 2010; Nakazawa et al., 2011; Punzo et al., 2009; Sieving et al., 2006), and (2) those attempting to restore retinal photosensitivity. The latter includes electronic retinal implants (Chader et al., 2009; Zrenner, 2002; Zrenner et al., 2011), optogenetic approaches (Busskamp et al., 2012), and cell implantation therapies (Gust and Reh, 2011; MacLaren et al., 2006; West et al., 2010). An effective cell therapy can act through different mechanisms: transplanted cells may secrete trophic/neuroprotective factors to slow degeneration or provide new photoreceptors to replace lost cells. In the latter case not only implanted cells need to survive and function as phototransducers, but they also have to form functional synapses with second order retinal neurons. Moreover, implanted photoreceptor cells cannot survive and be active without a functional RPE that almost 
invariably is affected at some stage of the disease process. Developing a combined RPE/photoreceptor sheet for transplantation might be a solution in the future, but at present cell therapy approaches are focusing on the implantation of one cell type (either photoreceptor or RPE cells) selecting conditions where the other cell type is still present. This approach appears more feasible in diseases where RPE cells degenerate first, subsequently leading to photoreceptor loss and thus to blindness, as it occurs in some common macular diseases, like dry AMD and STGD. As functional recovery depends on photoreceptor rescue by implanted healthy RPE cells, it will be critical to treat patients early in the disease process and before extensive damage occurs. Although success rates are not high, case numbers low and no long-term follow-up is available, the positive outcomes described in some patients treated with macular translocation and RPE patch grafts confirmed that replacement of diseased RPE can improve vision and thus are encouraging the development of new cell-replacement therapeutic approaches (Ong and da Cruz, 2012; Skaf and Mahmoud, 2011). Developing a safe therapy with RPE cells might become useful in the treatment of many of the retinal degenerative diseases affecting the RPE-photoreceptor complex. After several attempts to transplant the retina, researchers are still evaluating the molecular features characterizing cells with the ability to generate a functional RPE suitable for cell therapy of the diseased retina.

There are several elements that researchers need to account for when developing such therapeutic tools. Therapeutic potentials and transplantation procedures have to face the need for 40,000-60,000 RPE cells to replace the macula area (Lu et al., 2009). Current Good Manufacturing Practices (cGMPs) are required to monitor the facility, processes, testing, and practices to produce a consistently safe and effective product for human use. In the context of clinical manufacturing of a cell therapy product Current Good Tissue 
Practices (cGTP) are also required to oversee donor consent, traceability, and infectious disease screening.

Transplantation of allogenic or autologous RPE aims at replacing pathological RPE with healthy tissue. Several cell sources have been evaluated for RPE replacement therapies including immortalized cell lines (i.e. ARPE19) as well as other non-RPE cell lines or sheets of fetal and adult RPE (Pinilla et al., 2007; Algvere et al., 1997; Chen et al., 2009; Tezel et al., 2007). Autologous peripheral RPE have also been transplanted in AMD patients (Binder et al., 2002; van Meurs and Van Den Biesen, 2003). Only partial rescue of vision could be shown in these studies and translation into the clinic was hindered by the limited accessibility to these cells or by ethical concerns. Furthermore, prenatal tissue may be very variable with regards to quality. Lately, studies focused on the search of new cell sources to overcome these limitations and to offer in vitro culture techniques that allow the expansion of homogeneous cells to gain numbers suitable for cell replacement therapies.

\section{Generating RPE in vitro}

\subsection{Embryonic stem cells and induced pluripotent stem cells as sources of RPE}

Embryonic stem cells (ESCs) originate from the inner cell mass of the mammalian embryo at the blastocyst stage that is reached at 5 days post-fertilization in humans. Stem cells can be classified according to the range of cell types they can differentiate into: pluripotent stem cells can give rise to all embryonic cell types and multipotent stem cells have the ability to differentiate only in a limited number of cell types related to the tissue from which the stem cell derived from. ESCs are defined as pluripotent cells, able to proliferate indefinitely and to differentiate into any cell type given the appropriate environment and stimuli. 
ESCs have been envisaged as an important source to generate RPE in vitro in sufficient amount for transplantation purposes. Differentiation methods both for mouse and human ESCs are based on either spontaneous or defined culture procedures (Ramsden et al., 2013). In order to induce spontaneous differentiation, ESCs were grown to confluence on a feeder layer of PA6 stromal cells and when basic fibroblast growth factor (bFGF) was withdrawn from the culture medium pigmented clones spontaneously formed and were subsequently isolated and expanded (Kawasaki et al., 2002). A second protocol required that ESC were first grown as embryoid bodies and then plated on dishes coated either with laminin and fibronectin or with gelatin until they formed visible pigmented colonies (Lu et al., 2009; Osakada et al., 2008). The RPE tissue generated by these methods expressed many RPE-specific proteins, formed tight junctions and showed apical-basal polarity. Molecularly directed methods to differentiate RPE from ESCs were based on blocking the Wnt and Nodal signaling pathways or on exposure to Nicotinamide and Activin A or on treatment with bFGF, Retinoic acid and Sonic hedgehog (Idelson et al., 2009; Osakada et al., 2009; Zahabi et al., 2012). ESC-derived pigmented cells could form a cell monolayer with polygonal actin bundles, as defined by the staining with F-actin, and with tight-junctions as shown by localization of the tight junction protein zona occludens 1 (ZO-1). These cells were shown to express PAX6, at levels similar to fetal RPE, and MITF, a key regulator of RPE differentiation (Bharti et al., 2012). The presence of mature RPE specific markers, such as the visual cycle enzyme RPE65, could also be demonstrated. Ultrastructural analysis revealed that ESC-derived RPE formed a polarized tissue with apical microvilli. Electron microscopy also showed melanosomes mostly at the apical side of the cells. Molecularly controlled differentiation procedures, however, required very long culture times and, so far, did not show enough benefits compared to the spontaneous method to justify their application for therapeutic purposes. 
Given the origin of ESCs it is clear that the prospective application of their derivatives to cell transplantation in patients may raise significant ethical concerns. More recently, a new source of pluripotent cells was developed from adult murine somatic cells, such as fibroblasts, that could be reprogrammed to a pluripotent state by misexpression of four transcription factors: OCT4, SOX2, KLF4, c-MYC (OSKM). The reprogrammed cells were called induced pluripotent stem cells (iPSCs) (Takahashi and Yamanaka, 2006). iPSCs share all the desirable self-renewal and pluripotency characteristics of ESCs, without carrying the ethical burden associated to the use of human embryos. Furthermore, iPSCs can be derived from patients, thus allowing for the development of personalized cell therapies and of in vitro models for molecular studies of diseases. Protocols for RPE differentiation of ESCs were also successfully applied to murine and human iPSCs, showing their equivalence to ESCs (Hirami et al., 2009; Osakada et al., 2009).

Provided that many ethical obstacles can be overcome by the use of iPSC derived RPE, the in vitro generated tissue can be envisaged as a promising source for cell replacement therapies because it displays many of the features of native RPE such as pigmentation, apical-basal polarity, tight-junctions, phagocytosis activity and expression of enzymes for the visual cycle. The eye is also an immune-privileged location thanks to the blood-retina barrier making this organ a favorable site for tissue transplantation therapies.

Pre-clinical evaluation of integration competence of in vitro differentiated cells were undertaken by subretinal injections of human ESC-derived RPE into retinal degeneration rodent models or into the immune-deficient NIH III mouse model (Haruta et al., 2004; Lu et al., 2009). Visual acuity was measured by optomotor response in a mouse model for STGD and a rat model of RP. This test revealed a rescue of spatial acuity when at least 50,000 cells were injected. Luminance threshold responses recorded across the superior colliculus showed that the area with the best sensitivity was the treated area. Treated eyes 
maintained better luminance thresholds five months after surgery when compared to the contralateral uninjected eye that had lost light sensitivity at this age. Rescue was confirmed by histological analysis showing integration of human donor RPE cells into the host RPE layer. Additionally, subretinal transplantation of RPE derived from human iPSCs

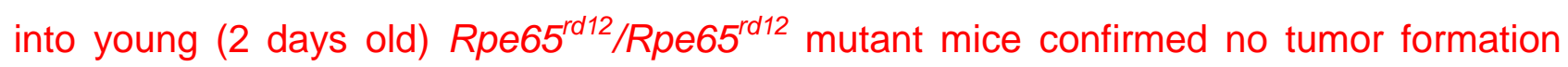
from transplanted cells and, most importantly, restoration of vision as measured by ERG at the age of 6 months (Li et al., 2012). Finally, a safety study demonstrated that ESCderived RPE did not form teratomas when injected into immune-deficient NIH III mice up to 9 months after transplantation (Lu et al., 2009).

These studies paved the way for clinical applications in patients. A cell line of ESC-derived RPE called MA09-hRPE was used in phase I and II clinical trials. MA09-hRPE cells were injected into the submacular space of one patient affected by STGD and one patient affected by dry AMD. The follow-up at four months did not show any evidence of teratoma formation and no loss of vision in treated eyes. Some vision improvement was reported (Schwartz et al., 2012).

\subsection{Adult RPE as a source of RPE}

Mature RPE cells are mitotically quiescent under physiological conditions in the eye. Several studies on amphibians showed that, upon injury, the RPE could proliferate and regenerate both RPE and neural retina. These findings demonstrated intrinsic plasticity of RPE cells and ability to transdifferentiate. These observations also suggested that the RPE has some capacity for self-repair upon proper stimuli. Plasticity of the human RPE cells was also uncovered in pathological conditions, for example in proliferative vitreoretinopathy, in which epithelial-mesenchymal transition and proliferation was reported (Casaroli-Marano et al., 1999). RPE cultures derived from adult human donors could be 
propagated in vitro, however the identification of two phenotypically distinct cell populations suggested some heterogeneity in the culture (McKay and Burke, 1994). Long post-confluent periods were required for adult RPE cells to form tissue sheets and mature adherens junctions (Kaida et al., 2000). The prospective use of adult RPE in regenerative therapy was recently reconsidered when a subpopulation of RPE cells was discovered to exhibit self-renewal ability in vitro and multipotentiality (Salero et al., 2012). After dissociation of RPE cells from human donor eyes, pigmented cells were able to reactivate proliferation when plated on an adherent substrate in the presence of growth factors from serum. Cells could reach confluence and formed a cobblestone monolayer that expressed several RPE specific genes but at lower levels compared to adult RPE. These cells highly expressed $c-M Y C$ and KLF4 but not other stemness markers such as OCT4 and NANOG. About $10 \%$ of the primary culture cells could be passaged and expanded in vitro to form new cobblestone RPE monolayers (Salero et al., 2012). Although the source of RPE cells from adult eyes could open interesting perspectives to autologous transplantation, expression of genes involved in cell proliferation and cancer in these cultures may act as a drawback in the use of this tissue source for cell therapy because of the possible development of tumors from the transplanted cells. Complete in vitro differentiation into a mature RPE monolayer prior to transplantation was recently shown to limit these harmful outcomes (Stanzel et al., 2014).

\subsection{Retinal neurospheres (RNS) as source of RPE}

Retinal stem cells (RSCs) have been identified in the adult ciliary body and these cells can be cultured in vitro as pigmented neurospheres. The procedure requires dissection of the ciliary epithelium followed by dissociation of the cells and culture at very low density to generate floating clones of pigmented cells called retinal neurospheres (RNS) (Ahmad et 
al., 2000; Tropepe et al., 2000). Molecular analysis of these cells showed that they derive from large pigmented ciliary epithelial cells expressing low levels of P-cadherin (Ballios et al., 2012). Pigmented RNS can be obtained from different species such as man, rat, mouse, pig and rabbit (Coles et al., 2004; Gu et al., 2007; Inoue et al., 2005; Ahmad et al. 2000) and are visible within one week of in vitro culture with serum-free DMEM-F12 medium in the presence of hormones and defined doses of growth factors. RNS show a limited ability to be expanded in vitro because only a small proportion of cells in a neurosphere have self-renewal capability. Since in vitro expansion is very important to obtain large amount of cells necessary for therapeutic purposes, the protocol for in vitro culture and propagation was ameliorated by treatment with PEDF, a potent antiangiogenic and neuroprotective agent of the retina (De Marzo et al., 2010). Molecular characterization implied that RNS have features of retinal progenitors. Interestingly, when compared to ESCs, RNS expressed much higher levels of retinal neuroblast transcription factors (PAX6, CHX10 and RAX) but lower levels of NANOG, OCT3/4 and SOX2, suggesting that RNS contained cells with characteristics of retinal progenitors with only a small population of stem cells (Demontis et al., 2012). RNS from the adult ciliary epithelium are therefore colonies of a mixed population of cells exhibiting retinal stem and progenitor nature. Ultrastructural analysis confirmed some heterogeneity in the cells composing RNS and identified a central area characterized by polymorph cells with cytoplasmic processes and a peripheral area characterized by flat, elongated and polarized epithelial-like cells containing melanosomes (Moe et al., 2009).

RNS from rodent ciliary bodies could be induced to differentiate into all neural retinal cell types and into RPE (Aruta et al., 2011; Tropepe et al., 2000; Vossmerbaeumer et al., 2008). Differentiation into rod photoreceptors was optimized in vitro by culturing with DMEM-F12 supplemented with defined factors in the presence of bFGF (Ballios et al., 
2012; Demontis et al., 2012). Otherwise, differentiation of murine RNS into RPE required plating of RNS onto extracellular matrix from Engelbreth-Holm-Swarm murine sarcoma (ECM) and switching the culture medium from DMEM-F12 to DMEM in the absence of bFGF. DMEM supplemented with serum and hormones (Hydrocortisone, Selenious acid, Linoleic acid, Insulin, Transferrin, Putrescine and Triiodothyronine) allowed the generation of a RPE monolayer (Aruta et al., 2011). Initially cells migrated out of the RNS and lost pigmentation but after 7 days in culture, when cells reached confluence, they started to pigment again. During this time in culture, cells specifically differentiated into RPE as demonstrated by change of expression of the different isoforms of the pigment cell master gene Mitf. Differentiated cells specifically expressed a RPE specific isoform of Mitf, i.e. $\mathrm{H}$ Mitif, and switched off M-Mitf which is typical of skin and choroidal melanocytes (Bharti et al., 2008). In vitro differentiated cells expressed the melanin biosynthesis enzymes Tyrosinase, Tyrosinase-related protein 1 and Dopachrome tautomerase and as well as genes important for melanosome biogenesis and transport such as Pmel17, Matp, Oca2, Oa1, Mlana and Myo7a. RNS could be induced to differentiate into a monolayer of pigmented cells connected by tight-junctions and gap-junction, labeled by ZO-1 and Connexin 43 , respectively. A longer differentiation time was required to detect expression of markers characteristic of mature RPE such as Rpe65, the visual cycle enzyme. At this time of differentiation cells showed a polarized phenotype characterized by the basolateral membrane localization of Bestrophin 1 and the apical localization of Ezrin, $\beta_{5}$-integrin and $\mathrm{Na}^{+} / \mathrm{K}^{+}$ATPase. Electron microscopy analysis showed melanosomes at different differentiation stages and with an elongated shape typical of RPE melanosomes. This study also demonstrated phagocytosis activity in RNS-derived RPE cells that were able to uptake POS by binding to $\alpha v \beta_{5}$ integrin and internalization mediated by Mertk. 
Published studies on the murine tissue suggested that the ciliary body can be a promising source of cells to generate RPE for transplantation purposes (Aruta et al., 2011). While ESCs are already used in clinical trials and are paving the way for subretinal transplantation procedures, there is still need for accessible sources of cells without the ethical burdens of ESC. The ciliary body appears to be a fairly accessible tissue that can be easily collected from post-mortem donors. Nevertheless, in case efficient isolation techniques become available, partial ciliectomy surgical procedures may be considered on patients to allow autologous transplantation. Here we will discuss improvement of the procedures to generate a highly pigmented and differentiated human RPE tissue that may provide a source for cell therapy approaches in the future.

\section{Generation of human RNS from post-mortem donations}

\subsection{Tissue collection and dissociation}

The procedures of the present study involving human participants were approved by the local ethical committee, and were conducted in accordance with the principles of the Declaration of Helsinki (http://www.wma.net/en/60about/70history/01declarationHelsinki/). Human ciliary bodies were collected from deceased donors after their legal representatives had expressed a written informed consent for the inclusion in the study. Donors were not affected by retinal degeneration and had an age between 70 and 85 years. After disinfection with povidone iodine, the conjunctiva and Tenon's capsule were dissected for 12 clock hours and a concentric scleral cut was performed 12 clock hours with a blade and curved scissors preserving the integrity of the uveal tissue. The corneoscleral graft was then explanted and a circular cut was done posteriorly to the pars plicata and containing the ciliary bodies. The ciliary bodies, the lens and the iris 
were finally explanted en-bloc and preserved at $4^{\circ} \mathrm{C}$ in a synthetic media for corneal storage (EUSOL-C $\left.{ }^{\circledR}\right)$.

For cell preparation, the iris was separated from the pars plicata, and the lens and the capsule were removed. The cleaned pars plicata was cut into 4 portions and treated with $2 \mathrm{mg} / \mathrm{ml}$ of dispase in DMEM-F12 medium for $30 \mathrm{~min}$ at $37^{\circ} \mathrm{C}$. The pieces of ciliary body were then moved to a solution containing $1.3 \mathrm{mg} / \mathrm{ml}$ of trypsin and $0.67 \mathrm{mg} / \mathrm{ml}$ of hyaluronidase and incubated for 20 minutes at $37^{\circ} \mathrm{C}$. The ciliary body epithelium was scraped from the ciliary muscle and dissociated to a single cell suspension (for a detailed protocol see Giordano et al., 2007). We obtained an average of $6 \times 10^{5}$ cells per eye.

\subsection{RNS culture}

Cells dissociated from the ciliary body were seeded at the density of 20,000 cells $/ \mathrm{ml}$ and cultured with DMEM-F12 medium added with N2 supplement (Gibco), 20ng/ml of EGF and $20 \mathrm{ng} / \mathrm{ml}$ of bFGF. Floating clones of cells were visible 2-3 days after plating. Clones consisted of pigmented cells that did not attach to the plastic substrate of the Petri dish (Figure 3A), as previously published for RNS (Aruta et al., 2011; Demontis et al., 2012; Giordano et al., 2007). After 7 days in culture RNS reached a diameter of about $100 \mu \mathrm{m}$ (Figure 3A-C). At different time points cell proliferation in RNS was assessed by exposure to $10 \mu \mathrm{M}$ BrdU (5-bromo-2'-deoxyuridine) for 3 hours followed by immunofluorescence with an anti-BrdU antibody to detect the newly incorporated nucleotide in the genomic DNA. Cells in the RNS were actively proliferating during the first days of culture when most nuclei were positive to BrdU staining (Figure 3D). The number of proliferating cells decreased with time in culture and no proliferation could be detected after 9 days (Figure $3 E-F)$. Based on the proliferation assay we chose to start differentiation of RNS at the $7^{\text {th }}$ day of culture. 


\section{In vitro differentiation of RNS into human RPE}

\subsection{Differentiation of RPE sheets from RNS}

We modified the published protocol for murine RNS and we seeded human RNS cells after dissociation for $30 \mathrm{~min}$ with Accutase $^{\mathrm{TM}}$ (Millipore). We obtained about $1.2 \times 10^{5}$ cells per eye that underwent differentiation into RPE. Dissociated cells were seeded on an ECM substrate at the concentration of 23,000 cells $/ \mathrm{cm}^{2}$ and cultured for 2 days with the RNS growth medium containing bFGF and EGF. On the $3^{\text {rd }}$ day of culture growth factors were withdrawn and cells were exposed to differentiation medium as previously published (Aruta et al., 2011). Cells actively proliferated during the first days of differentiation and proliferation was still high after 7 days of culture (75\%, Figure $3 \mathrm{G}-\mathrm{H}$ and $\mathrm{M}$ ). Interestingly, proliferation could be detected in poorly pigmented cells (Figure 3G, red arrows). After 14 days of differentiation the number of BrdU labeled cells decreased to less than $10 \%$ and after 21 days of culture proliferating cells were approximately $3 \%$ (Figure 3I-M). The decreasing number of proliferating cells correlated with increased differentiation and pigmentation, since we observed BrdU positive cells only in poorly pigmented regions (Figure 3G-L). After 21 days of culture in differentiation medium cells formed a pigmented monolayer (Figure 3K).

\subsection{Molecular characterization of the in vitro generated RPE}

Molecular characteristics of the RPE cells derived from RNS in vitro were evaluated by immunofluorescence analysis, western blotting and real-time qPCR. The specificity of staining with different antibodies was confirmed using the Madin-Darby Canine Kidney (MDCK) epithelial cell line as control (Figure 4C, F, I, L, O). We first assessed the 
formation of tight junctions by immunostaining with an antibody against the protein ZO1. ZO1 displayed membrane localization in cells after 21 days of differentiation when they formed a confluent monolayer of polygonal cells (Figure 4A-B). Polarization of the RPE cells was assessed with three markers: $\beta 5$-integrin and ezrin which are located at the apical side of the RPE and bestrophin 1 at the basolateral membrane. $\beta 5$-integrin, necessary for binding of POS during phagocytosis, could be detected with an apical localization in cells at all differentiation time points (Figure 4D-E and P). Similarly, Ezrin showed an apical localization at 7 and 21 days of differentiation (Figure 4G-H). Bestrophin 1 showed basolateral localization at all time points, as expected in RPE cells (Figure 4J-K and Q). We also evaluated the expression of visual cycle enzymes either by immunofluorescence or western blotting. We could detect LRAT inside the RPE cells, as demonstrated by confocal microscopy (Figure 4M-N). RPE65 was clearly present in RPE cells after 21 days of differentiation in vitro but the amount of protein was much lower compared to adult human RPE (Figure 5A-B). Similarly, CRALBP, necessary for the binding of retinoids inside the RPE, was observed at all times of differentiation but at lower levels compared to expression in mature human RPE (Figure 5A-B).

A key transcription factor necessary for RPE differentiation is MITF. MITF is characterized by different isoforms and H-MITF is one of the isoforms specific for RPE cells and is not expressed by other pigmented cells of the eye (Bharti et al., 2008). Primers for real-time qPCR were designed such as they could discriminate at the mRNA level among several MITF isoforms (Aruta et al., 2011). Expression of the RPE specific H-MITF isoform showed highest expression levels at 21 days of differentiation (Figure 5C). Interestingly, expression increased with differentiation and the levels at 21 days were higher than in the adult human RPE. To confirm that the MITF transcription factor localized, as expected, in the nuclei of RPE cells we used an anti-MITF antibody and found very low MITF in RPE cells 
differentiated for 7 days. Strong and nuclear specific immunostaining was observed in RPE cells after 14 days of differentiation (Figure 5D-E).

Finally, we wanted to define if in vitro differentiated RPE expressed PEDF, a trophic factor with neuroprotective properties (Barnstable and Tombran-Tink, 2004). RPE cells differentiated for 21 days showed a detectable expression of PEDF mRNA although expression levels were much lower compared to adult RPE (Figure 5F). Progressive pigmentation of cells with differentiation time inferred that melanin synthesis enzymes were active in the RPE cultures (Figure 3G, I and K). We thus also assessed expression of one of the genes important for melanosome biogenesis, OA1. OA1 transcripts could be detected after 21 days of differentiation and displayed higher levels than in the adult RPE (Figure 5G). It is known that melanosomes are not actively regenerated in the fully mature RPE and therefore some genes involved in melanogenesis are down-regulated in adult RPE. The observation of a higher level of OA1 mRNA in RPE cells in vitro compared to the RPE from adult donors may be explained by the fact that RPE cultures at 21 days have not reached full maturation, as also suggested by the levels of expression of other RPE markers (Figure 5A-C). Consistent with this hypothesis a previous report showed that the OA1 gene is expressed at low levels in adult RPE (Surace et al., 2000).

\subsection{Phagocytosis activity of RPE cells in the newly formed sheets of tissue}

A phagocytosis assay was performed to test one of the functions of RPE cells in the tissue differentiated in vitro. To define the phagocytic ability of in vitro differentiated RPE we used fluorescein labeled bovine POS, as previously published (Aruta et al., 2011). RPE cells differentiated for 21 days were fed for 1 or 3 hours with POS. We assessed whether RPE cells were able to internalize fluorescein labeled POS by confocal microscopy. Intracellular localization of POS in RPE cells confirmed the phagocytic ability of the RPE tissue 
differentiated in vitro (Figure $5 \mathrm{H}$ ). Increased internalization of POS was observed over time of exposure (Figure 5I), in agreement with studies of phagocytosis in primary RPE cell cultures (Kennedy et al., 1994).

\section{Future directions}

In vitro differentiated human RPE derived from ESCs have been transplanted subretinally as cell suspension for the treatment of AMD and STGD in phase I and II clinical trials (Clinical Trial ID\# NCT01344993, NCT01226628). Initial reports confirmed that the treatment is safe but the efficacy is still under review. The scientific community is still debating the best cell source for RPE transplantation. Technical and clinical limitations should also be considered and among them the surgical procedure that may require either injection of a cell suspension or transplantation of RPE tissue sheets, the number of cells necessary for effective treatments, immunogenic responses and ethical issues.

In this paper we discussed different cell sources for RPE transplantation, such as fetal tissue, adult RPE cells, ESCs and iPSCs as well as RSCs. Some of the limitations in the use of fetal sources for transplantation of RPE reside in the variable quality of the tissue after harvest and in the immunogenicity. ESCs and iPSCs exhibit clinically appealing features including limited immunogenicity and, for iPSCs, the possibility to use an autologous cell source. Unlike iPSCs or other potential modalities of autologous cell transplantation, ESCs cells are allogenic hence they carry the drawback of not being genetically matched to the recipient patient. Cell therapies using allogenic lines may induce immune response in the host, leading to the rejection of the transplanted cells. Immunosuppressive therapy may be used to prevent and counteract the immune reaction, but its side effects can be severe. The development of technologies capable of reducing 
the immunogenicity of in vitro expanded RPE cells, or even to ensure immunological compatibility with the patient would definitely facilitate the application of cell therapies. iPSCs express low levels of MHC class one and $\beta 2$-microglobin proteins at their surface but expression of these proteins increases upon differentiation into RPE (Kamao et al., 2014). Hence grafts of in vitro differentiated RPE derived from allogenic iPSC may evoke immune response with subsequent rejection. Furthermore, the surgical procedure for transplantation can induce some degree of inflammation to which the transplanted tissue will be exposed. Another complication of the surgery can be the possible reflux of transplanted cells into the vitreous that may be dangerous and cause proliferative vitreoretinopathy (PVR). PVR is the main complication following retinal detachment surgery or retinal injury. It is characterized by migration and proliferation of retinal cells onto the retinal surface and into the vitreous. Although they are not the only cell type involved, RPE cells play a major role in the pathogenesis of PVR (Casaroli-Marano et al., 1999; Leaver, 1995).

Implants of an adult RPE cell suspension have been tried as autologous transplants but drawbacks were found in the difficulty to collect enough cells to repopulate the macula area and in the limited competence of cells in suspension to attach to a diseased Bruch's membrane and to form a functional RPE monolayer in AMD patients (Sheridan et al., 2004). Transplantation of a polarized RPE monolayer as a sheet is thus envisaged as the most promising protocol for successful rescue of vision in patients. In fact, the apicobasal polarity is essential for the RPE functionality. The basal and basolateral sides need to be properly organized to ensure a functional outer blood-retina barrier. The apical microvilli for phagocytosis of POS and transfer of retinoids in the visual cycle are also important. A comparison of transplantation of cell suspensions versus RPE sheets both differentiated from iPSC was evaluated in monkeys. RPE cells transplanted as a cell suspension 
accumulated at the lower margin of the induced retinal detachment and some cells refluxed into the vitreous. RPE transplanted as a sheet was detected in the transplanted site and, in case of autograft transplant using iPSC derived from a biopsy from the same monkey, did not show signs of rejection one year after surgery (Kamao et al., 2014). Several studies are evaluating the best substrate for the culture of a continuous RPE monolayer (Sheridan et al., 2004). The identification of a clinically usable artificial scaffold is still under study because biodegradable membranes can cause inflammation and nondegradable membranes can interfere with functional exchanges between the RPE and the choroid.

The most appealing feature of the RPE tissue differentiated in vitro is the possibility to expand the cells before differentiation. In this study we presented a new possible source of human RPE from RSCs culture as RNS. The advantage of RPE derived from RNS is the relatively large availability of the cell source, as ciliary bodies can be collected from postmortem donors for allograft transplantation. Secondly, the possibility of autologous transplantation upon partial ciliectomy surgery may be evaluated. We showed that a single donor can provide enough cells for several transplants so partial ciliectomy may provide enough cells for autologous transplantation. On the other hand, autologous transplantation from patients with genetic RPE defects would require an ex-vivo gene therapy correction of the genetic mutation prior to the in vivo use of the tissue. The protocol of RPE differentiation from RNS required limited cell expansion in vitro and short time in culture compared to ESC or iPSC. Short cultures will limit possible chromosomal aberrations that are linked to cell transformation. In fact, a disadvantage of ESCs and iPSCs in clinical applications is the possibility of tumor formation from residual undifferentiated cells in the RPE cell product for transplantation. Tumorigenicity tests were recently performed on RPE derived from iPSC via subcutaneous and subretinal administration and this RPE source 
had a negligible tumorigenic potential (Kanemura et al., 2014). RNS-derived RPE tissue has not been evaluated in tumorigenicity tests yet, but data shown in this study provided evidence that RPE derived from RNS stopped proliferation upon differentiation. Further analyses will be required to fully characterize RNS-derived RPE and its characteristics when cultured on matrixes suitable for tissue transplantation.

Another issue discussed more recently in transplantation studies is the differentiation stage that RPE cells need to reach before transplantation. Photoreceptors were shown to be able to integrate in the host tissue if they were postmitotic but not fully differentiated (MacLaren et al., 2006). Similarly, not heavily pigmented cells attached better to the Bruch's membrane suggesting that the control of in vitro differentiation before transplantation may allow optimization of cell survival and functionality (Schwartz et al., 2012). RPE cells derived from RNS did not reach a fully differentiated stage, based on the gene expression studies presented here. A full characterization of the differentiation level of this tissue will require microarray analysis followed by comparison with fetal and adult human RPE.

The ability of the recipient eye to accept the transplanted cells may also be affected by factors present in a fully differentiated tissue and by the unhealthy environment. The modulation of the recipient environment by ectopic expression of IGF1 helped the integration of transplanted cells in a photoreceptor transplantation murine model (West et al., 2012). It is possible that integration of RPE may also be facilitated by supplementation of growth factors during transplantation.

Finally, the success in restoring vision via cell therapy with RPE cells will ultimately depend on the presence of residual photoreceptors in the retina. Hence, it is critical that adequate diagnostic tools are available to accurately visualize and quantify photoreceptor cells, and to improve the characterization of the Bruch's membrane and choriocapillaris. 
The confocal near-infrared reflectance (NIR) imaging and the Spectral-domain optical coherence tomography (SD-OCT) were recently shown in preclinical studies to be able to detect transplanted human ESC derived RPE cells in Royal College of Surgeons (RCS) rat in vivo (Hu et al., 2012; Ribeiro et al., 2013). Most recent OCT technologies already provide high resolution images of the RPE-photoreceptor complex, but more advanced features would be desirable, such as extending high density 3D scanning to larger retinal areas, and automatizing the extraction of measurements from such high volume data. Such improvements in diagnostics tools will allow a more accurate classification and selection of the cases to be treated, a better identification of the preferred retinal location for cells transplantation, as well as more quantitative data in follow-up studies.

In conclusion, data from preclinical studies as well as ongoing clinical trials show evidence that the proposed stem cells sources (ESCs, iPSCs, RSCs) may all represent viable solutions for RPE transplantation, although a number of open questions need to be addressed by future studies in order to define the best option not only in terms of cell type, but also of tissue engineering and of surgical technique. Moreover, it is reasonable to expect that different options may become available in the future, and that their different features may be advantageous for different clinical situations. Finally, RPE transplantation might become part of complex therapeutic strategies in some diseases, e.g. STGD, in which RPE transplantation could be combined with gene therapy to halt the metabolic dysfunction of photoreceptors, hence protecting the newly implanted RPE cells. 


\section{Acknowledgments}

This study was funded by the Italian "Istituto Superiore di Sanita"-ERARE, Programma Strategico RARER-Programma di ricerca Regione-Università 2010-2012, and the Vision of Children Foundation. The authors would like to acknowledge the CIGS of University of Modena and Reggio Emilia for providing confocal microscopy assistance and E. Nandrot, K. Palczewski and M. Redmond for reagents. 


\section{References}

Ahmad, I., Tang, L., Pham, H., 2000. Identification of Neural Progenitors in the Adult Mammalian Eye. Biochem Biophys Res Commun 270, 517-521.

Algvere, P. V, Berglin, L., Gouras, P., Sheng, Y., Kopp, E.D., 1997. Transplantation of RPE in age-related macular degeneration: observations in disciform lesions and dry RPE atrophy. Graefes Arch Clin Exp Ophthalmol 235, 149-158.

Aruta, C., Giordano, F., De Marzo, A., Comitato, A., Raposo, G., Nandrot, E.F., Marigo, V., 2011. In vitro differentiation of retinal pigment epithelium from adult retinal stem cells. Pigment Cell Melanoma Res 24, 233-240.

Bainbridge, J.W.B., Smith, A.J., Barker, S.S., Robbie, S., Henderson, R., Balaggan, K., Viswanathan, A., Holder, G.E., Stockman, A., Tyler, N., Petersen-Jones, S., Bhattacharya, S.S., Thrasher, A.J., Fitzke, F.W., Carter, B.J., Rubin, G.S., Moore, A.T., Ali, R.R., 2008. Effect of gene therapy on visual function in Leber's congenital amaurosis. N Engl J Med 358, 2231-2239.

Ballios, B.G., Clarke, L., Coles, B.L.K., Shoichet, M.S., van der Kooy, D., 2012. The adult retinal stem cell is a rare cell in the ciliary epithelium whose progeny can differentiate into photoreceptors. Biol Open 1, 237-246.

Barnstable, C.J., Tombran-Tink, J., 2004. Neuroprotective and antiangiogenic actions of PEDF in the eye: molecular targets and therapeutic potential. Prog Retin Eye Res 23, $561-577$. 
Bassi, M.T., Schiaffino, M. V, Renieri, A., De Nigris, F., Galli, L., Bruttini, M., Gebbia, M., Bergen, A.A.B., Lewis, R.A., Ballabio, A., 1995. Cloning of the gene for ocular albinism type 1 from the distal short arm of the X chromosome. Nat Genet 10, 13-19.

Belyaeva, O. V, Korkina, O. V, Stetsenko, A. V, Kim, T., Nelson, P.S., Kedishvili, N.Y., 2005. Biochemical properties of purified human retinol dehydrogenase 12 (RDH12): catalytic efficiency toward retinoids and C9 aldehydes and effects of cellular retinolbinding protein type I (CRBPI) and cellular retinaldehyde-binding protein (CRALBP) on the oxi. Biochemistry 44, 7035-7047.

Berson, J.F., Harper, D.C., Tenza, D., Raposo, G., Marks, M.S., 2001. Pmel17 initiates premelanosome morphogenesis within multivesicular bodies. Mol Biol Cell 12, 34513464.

Bharti, K., Gasper, M., Ou, J., Brucato, M., Clore-Gronenborn, K., Pickel, J., Arnheiter, H., 2012. A Regulatory Loop Involving PAX6, MITF, and WNT Signaling Controls Retinal Pigment Epithelium Development. PLoS Genet 8, e1002757.

Bharti, K., Liu, W., Csermely, T., Bertuzzi, S., Arnheiter, H., 2008. Alternative promoter use in eye development: the complex role and regulation of the transcription factor MITF. Development 135, 1169-1178.

Bialek, S., Miller, S.S., 1994. K+ and Cl- transport mechanisms in bovine pigment epithelium that could modulate subretinal space volume and composition. J Physiol $475,401-417$.

Binder, S., Stolba, U., Krebs, I., Kellner, L., Jahn, C., Feichtinger, H., Povelka, M., Frohner, U., Kruger, A., Hilgers, R.-D., Krugluger, W., 2002. Transplantation of autologous 
retinal pigment epithelium in eyes with foveal neovascularization resulting from agerelated macular degeneration: a pilot study. Am J Ophthalmol 133, 215-225.

Brilliant, M.H., 2001. The mouse $\mathrm{p}$ (pink-eyed dilution) and human P genes, oculocutaneous albinism type 2 (OCA2), and melanosomal pH. Pigm Cell Res 14, $86-$ 93.

Burke, J.M., Cao, F., Irving, P.E., 2000. High levels of E-/P-cadherin: correlation with decreased apical polarity of Na/K ATPase in bovine RPE cells in situ. Invest Ophthalmol Vis Sci 41, 1945-1952.

Burke, J.M., Cao, F., Irving, P.E., Skumatz, C.M., 1999. Expression of E-cadherin by human retinal pigment epithelium: delayed expression in vitro. Invest Ophthalmol Vis Sci 40, 2963-2970.

Busskamp, V., Picaud, S., Sahel, J.A., Roska, B., 2012. Optogenetic therapy for retinitis pigmentosa. Gene Ther 19, 169-175.

Caberoy, N.B., Zhou, Y., Li, W., 2010. Tubby and tubby-like protein 1 are new MerTK ligands for phagocytosis. Embo J 29, 3898-3910.

Caldwell, R.B., McLaughlin, B.J., 1984. Redistribution of Na-K-ATPase in the dystrophic rat retinal pigment epithelium. J Neurocytol 13, 895-910.

Carlson, A., Bok, D., 1999. Polarity of 11-cis retinal release from cultured retinal pigment epithelium. Invest Ophthalmol Vis Sci 40, 533-537. 
Casaroli-Marano, R.P., Pagan, R., Vilaro, S., 1999. Epithelial-Mesenchymal Transition in Proliferative Vitreoretinopathy: Intermediate Filament Protein Expression in Retinal Pigment Epithelial Cells. Invest Ophthalmol Vis Sci 40, 2062-2072.

Chader, G.J., Weiland, J., Humayun, M.S., 2009. Artificial vision: needs, functioning, and testing of a retinal electronic prosthesis. Prog Brain Res 175, 317-332.

Chen, C., Thompson, D.A., Koutalos, Y., 2012. Reduction of all-trans-retinal in vertebrate rod photoreceptors requires the combined action of RDH8 and RDH12. J Biol Chem 287, 24662-24670.

Chen, F.K., Uppal, G.S., MacLaren, R.E., Coffey, P.J., Rubin, G.S., Tufail, A., Aylward, G.W., Da Cruz, L., 2009. Long-term visual and microperimetry outcomes following autologous retinal pigment epithelium choroid graft for neovascular age-related macular degeneration. Clin Exp. Ophthalmol 37, 275-285.

Chihara, E., Nao-i, N., 1985. Resorption of subretinal fluid by transepithelial flow of the retinal pigment epithelium. Graefes Arch Clin Exp Ophthalmol 223, 202-204.

Cideciyan, A. V, Aleman, T.S., Boye, S.L., Schwartz, S.B., Kaushal, S., Roman, A.J., Pang, J.-J., Sumaroka, A., Windsor, E.A.M., Wilson, J.M., Flotte, T.R., Fishman, G.A., Heon, E., Stone, E.M., Byrne, B.J., Jacobson, S.G., Hauswirth, W.W., 2008. Human gene therapy for RPE65 isomerase deficiency activates the retinoid cycle of vision but with slow rod kinetics. Proc Natl Acad Sci USA 105, 15112-15117.

Coles, B.L.K., Angenieux, B., Inoue, T., Del Rio-Tsonis, K., Spence, J.R., McInnes, R.R., Arsenijevic, Y., van der Kooy, D., 2004. Facile isolation and the characterization of human retinal stem cells. Proc Natl Acad Sci USA 101, 15772-15777. 
Cortese, K., Giordano, F., Surace, E.M., Venturi, C., Ballabio, A., Tacchetti, C., Marigo, V., 2005. The ocular albinism type 1 (OA1) gene controls melanosome maturation and size. Invest Ophthalmol Vis Sci 46, 4358-4364.

Cremers, F.P.M., van den Hurk, J.A.J.M., den Hollander, A.I., 2002. Molecular genetics of Leber congenital amaurosis. Hum Mol Genet 11, 1169-1176.

D'Cruz, P.M., Yasumura, D., Weir, J., Matthes, M.T., Abderrahim, H., LaVail, M.M., Vollrath, D., 2000. Mutation of the receptor tyrosine kinase gene Mertk in the retinal dystrophic RCS rat. Hum Mol Genet 9, 645-651.

De Marzo, A., Aruta, C., Marigo, V., 2010. PEDF promotes retinal neurosphere formation and expansion in vitro. Adv Exp Med Biol 664, 621-630.

Dell'Angelica, E.C., 2009. AP-3-dependent trafficking and disease: the first decade. Curr Opin Cell Biol 21, 552-559.

Demontis, G.C., Aruta, C., Comitato, A., De Marzo, A., Marigo, V., 2012. Functional and molecular characterization of rod-like cells from retinal stem cells derived from the adult ciliary epithelium. PLoS One 7, e33338.

Driessen, C.A., Janssen, B.P., Winkens, H.J., van Vugt, A.H., de Leeuw, T.L., Janssen, J.J., 1995. Cloning and expression of a cDNA encoding bovine retinal pigment epithelial 11-cis retinol dehydrogenase. Invest Ophthalmol Vis Sci 36, 1988-1996.

Eagle, R.C., Lucier, A.C., Bernardino, V.B., Yanoff, M., 1980. Retinal pigment epithelial abnormalities in fundus flavimaculatus: a light and electron microscopic study. Ophthalmology 87, 1189-1200. 
Finnemann, S.C., 2003. Focal adhesion kinase signaling promotes phagocytosis of integrin-bound photoreceptors. Embo J 22, 4143-4154.

Finnemann, S.C., Bonilha, V.L., Marmorstein, A.D., Rodriguez-Boulan, E., 1997.

Phagocytosis of rod outer segments by retinal pigment epithelial cells requires $v 5$ integrin for binding but not for internalization. Proc Natl Acad Sci USA 94, 1293212937.

Frasson, M., Sahel, J.A., Fabre, M., Simonutti, M., Dreyfus, H., Picaud, S., 1999. Retinitis pigmentosa: rod photoreceptor rescue by a calcium-channel blocker in the rd mouse. Nat Med 5, 1183-1187.

Fuhrmann, S., Levine, E.M., Reh, T.A., 2000. Extraocular mesenchyme patterns the optic vesicle during early eye development in the embryonic chick. Development 127, 4599-4609.

Futter, C.E., Ramalho, J.S., Jaissle, G.B., Seeliger, M.W., Seabra, M.C., 2004. The role of Rab27a in the regulation of melanosome distribution within retinal pigment epithelial cells. Mol Biol Cell 15, 2264-2275.

Gal, A., Li, Y., Thompson, D.A., Weir, J., Orth, U., Jacobson, S.G., Apfelstedt-Sylla, E., Vollrath, D., 2000. Mutations in MERTK, the human orthologue of the RCS rat retinal dystrophy gene, cause retinitis pigmentosa. Nat Genet 26, 270-271.

Gallemore, R.P., Hernandez, E., Tayyanipour, R., Fujii, S., Steinberg, R.H., 1993. Basolateral membrane $\mathrm{Cl}$ - and $\mathrm{K}+$ conductances of the dark-adapted chick retinal pigment epithelium. J Neurophysiol 70, 1656-1668. 
Giordano, F., Bonetti, C., Surace, E.M., Marigo, V., Raposo, G., 2009. The ocular albinism type 1 (OA1) G-protein-coupled receptor functions with MART-1 at early stages of melanogenesis to control melanosome identity and composition. Hum Mol Genet 18, $4530-4545$.

Giordano, F., De Marzo, A., Vetrini, F., Marigo, V., 2007. Fibroblast growth factor and epidermal growth factor differently affect differentiation of murine retinal stem cells in vitro. Mol Vis 13, 1842-1850.

Gomes, N.L., Greenstein, V.C., Carlson, J.N., Tsang, S.H., Smith, R.T., Carr, R.E., Hood, D.C., Chang, S., 2009. A comparison of fundus autofluorescence and retinal structure in patients with Stargardt disease. Invest Ophthalmol Vis Sci 50, 3953-3959.

Gu, P., Harwood, L.J., Zhang, X., Wylie, M., Curry, W.J., Cogliati, T., 2007. Isolation of retinal progenitor and stem cells from the porcine eye. Mol Vis 13, 1045-1057.

Gust, J., Reh, T.A., 2011. Adult donor rod photoreceptors integrate into the mature mouse retina. Invest Ophthalmol Vis Sci 52, 5266-5272.

Hall, M.O., Obin, M.S., Heeb, M.J., Burgess, B.L., Abrams, T.A., 2005. Both protein S and Gas6 stimulate outer segment phagocytosis by cultured rat retinal pigment epithelial cells. Exp Eye Res 81, 581-591.

Hall, M.O., Prieto, A.L., Obin, M.S., Abrams, T.A., Burgess, B.L., Heeb, M.J., Agnew, B.J., 2001. Outer segment phagocytosis by cultured retinal pigment epithelial cells requires Gas6. Exp Eye Res 73, 509-520.

Hamel, C., 2006. Retinitis pigmentosa. Orphanet J Rare Dis 1, 40. 
Haruta, M., Sasai, Y., Kawasaki, H., Amemiya, K., Ooto, S., Kitada, M., Suemori, H., Nakatsuji, N., Ide, C., Honda, Y., Takahashi, M., 2004. In Vitro and In Vivo Characterization of Pigment Epithelial Cells Differentiated from Primate Embryonic Stem Cells. Invest Ophthalmol Vis Sci 45, 1020-1025.

Harvey, P.S., King, R.A., Summers, C.G., 2006. Spectrum of foveal development in albinism detected with optical coherence tomography. J AAPOS 10, 237-242.

Hauswirth, W.W., Aleman, T.S., Kaushal, S., Cideciyan, A. V, Schwartz, S.B., Wang, L., Conlon, T.J., Boye, S.L., Flotte, T.R., Byrne, B.J., Jacobson, S.G., 2008. Treatment of leber congenital amaurosis due to RPE65 mutations by ocular subretinal injection of adeno-associated virus gene vector: short-term results of a phase I trial. Hum Gene Ther 19, 979-990.

Hirami, Y., Osakada, F., Takahashi, K., Okita, K., Yamanaka, S., Ikeda, H., Yoshimura, N., Takahashi, M., 2009. Generation of retinal cells from mouse and human induced pluripotent stem cells. Neurosci Lett 458, 126-131.

Höfer, D., Drenckhahn, D., 1993. Molecular heterogeneity of the actin filament cytoskeleton associated with microvilli of photoreceptors, Müller's glial cells and pigment epithelial cells of the retina. Histochemistry 99, 29-35.

Holekamp, N.M., Bouck, N., Volpert, O., 2002. Pigment epithelium-derived factor is deficient in the vitreous of patients with choroidal neovascularization due to agerelated macular degeneration. Am J Ophthalmol 134, 220-227. 
Housset, M., Samuel, A., Ettaiche, M., Bemelmans, A., Béby, F., Billon, N., Lamonerie, T., 2013. Loss of Otx2 in the adult retina disrupts retinal pigment epithelium function, causing photoreceptor degeneration. J Neurosci 33, 9890-9904.

Houssier, M., Raoul, W., Lavalette, S., Keller, N., Guillonneau, X., Baragatti, B., Jonet, L., Jeanny, J.-C., Behar-Cohen, F., Coceani, F., Scherman, D., Lachapelle, P., Ong, H., Chemtob, S., Sennlaub, F., 2008. CD36 deficiency leads to choroidal involution via COX2 down-regulation in rodents. PLoS Med 5, e39.

Hu, Y., Liu, L., Lu, B., Zhu, D., Ribeiro, R., Diniz, B., Thomas, P.B., Ahuja, A.K., Hinton, D.R., Tai, Y.-C., Hikita, S.T., Johnson, L. V, Clegg, D.O., Thomas, B.B., Humayun, M.S., 2012. A novel approach for subretinal implantation of ultrathin substrates containing stem cell-derived retinal pigment epithelium monolayer. Ophthalmic Res 48, 186-191.

Idelson, M., Alper, R., Obolensky, A., Ben-Shushan, E., Hemo, I., Yachimovich-Cohen, N., Khaner, H., Smith, Y., Wiser, O., Gropp, M., Cohen, M.A., Even-Ram, S., BermanZaken, Y., Matzrafi, L., Rechavi, G., Banin, E., Reubinoff, B., 2009. Directed Differentiation of Human Embryonic Stem Cells into Functional Retinal Pigment Epithelium Cells. Cell Stem Cell 5, 396-408.

Inoue, Y., Yanagi, Y., Tamaki, Y., Uchida, S., Kawase, Y., Araie, M., Okochi, H., 2005. Clonogenic analysis of ciliary epithelial derived retinal progenitor cells in rabbits. Exp Eye Res 81, 437-445.

Jin, M., Li, S., Moghrabi, W.N., Sun, H., Travis, G.H., 2005. Rpe65 is the retinoid isomerase in bovine retinal pigment epithelium. Cell 122, 449-459. 
Kaida, M., Cao, F., Skumatz, C.M., Irving, P.E., Burke, J.M., 2000. Time at confluence for human RPE cells: effects on the adherens junction and in vitro wound closure. Invest Ophthalmol Vis Sci 41, 3215-3224.

Kaiser, P.K., 2013. Emerging therapies for neovascular age-related macular degeneration: drugs in the pipeline. Ophthalmology 120, S11-515.

Kamao, H., Mandai, M., Okamoto, S., Sakai, N., Suga, A., Sugita, S., Kiryu, J., Takahashi, M., 2014. Characterization of Human Induced Pluripotent Stem Cell-Derived Retinal Pigment Epithelium Cell Sheets Aiming for Clinical Application. Stem Cell Rep 2, $1-$ 14.

Kanemura, H., Go, M.J., Shikamura, M., Nishishita, N., Sakai, N., Kamao, H., Mandai, M., Morinaga, C., Takahashi, M., Kawamata, S., 2014. Tumorigenicity Studies of Induced Pluripotent Stem Cell (iPSC)-Derived Retinal Pigment Epithelium (RPE) for the Treatment of Age-Related Macular Degeneration. PLoS One 9, e85336.

Kawaguchi, R., Yu, J., Honda, J., Hu, J., Whitelegge, J., Ping, P., Wiita, P., Bok, D., Sun, H., 2007. A membrane receptor for retinol binding protein mediates cellular uptake of vitamin A. Science (80-. ). 315, 820-825.

Kawasaki, H., Suemori, H., Mizuseki, K., Watanabe, K., Urano, F., Ichinose, H., Haruta, M., Takahashi, M., Yoshikawa, K., Nishikawa, S.-I., Nakatsuji, N., Sasai, Y., 2002. Generation of dopaminergic neurons and pigmented epithelia from primate ES cells by stromal cell-derived inducing activity. Proc Natl Acad Sci USA 99, 1580-1585. 
Kennedy, C.J., Rakoczy, P.E., Robertson, T.A., Papadimitriou, J.M., Constable, I.J., 1994. Kinetic studies on phagocytosis and lysosomal digestion of rod outer segments by human retinal pigment epithelial cells in vitro. Exp Cell Res 210, 209-214.

Klevering, B.J., Deutman, A.F., Maugeri, A., Cremers, F.P.M., Hoyng, C.B., 2005. The spectrum of retinal phenotypes caused by mutations in the ABCA4 gene. Graefes Arch Clin Exp Ophthalmol 243, 90-100.

Koenekoop, R.K., 2009. Why do cone photoreceptors die in rod-specific forms of retinal degenerations? Ophthalmic Genet 30, 152-154.

Kojima, A., Nakahama, K.-I., Ohno-Matsui, K., Shimada, N., Mori, K., Iseki, S., Sato, T., Mochizuki, M., Morita, I., 2008. Connexin 43 contributes to differentiation of retinal pigment epithelial cells via cyclic AMP signaling. Biochem Biophys Res Commun 366, $532-538$.

Lagunowich, L.A., Grunwald, G.B., 1989. Expression of calcium-dependent cell adhesion during ocular development: a biochemical, histochemical and functional analysis. Dev Biol 135, 158-171.

Leaver, P.K., 1995. Proliferative vitreoretinopathy. Br J Ophthalmol 79, 871-872.

Léveillard, T., Sahel, J.-A., 2010. Rod-derived cone viability factor for treating blinding diseases: from clinic to redox signaling. Sci Transl Med 2, 26ps16.

Li, Y., Tsai, Y.-T., Hsu, C.-W., Erol, D., Yang, J., Wu, W.-H., Davis, R.J., Egli, D., Tsang, S.H., 2012. Long-term safety and efficacy of human-induced pluripotent stem cell (iPS) grafts in a preclinical model of retinitis pigmentosa. Mol Med 18, 1312-1319. 
Lu, B., Malcuit, C., Wang, S., Girman, S., Francis, P., Lemieux, L., Lanza, R., Lund, R., 2009. Long-term safety and function of RPE from human embryonic stem cells in preclinical models of macular degeneration. Stem Cells 27, 2126-2135.

MacLaren, R.E., Pearson, R.A., MacNeil, A., Douglas, R.H., Salt, T.E., Akimoto, M., Swaroop, A., Sowden, J.C., Ali, R.R., 2006. Retinal repair by transplantation of photoreceptor precursors. Nature 444, 203-207.

Maguire, A.M., Simonelli, F., Pierce, E.A., Pugh, E.N., Mingozzi, F., Bennicelli, J., Banfi, S., Marshall, K.A., Testa, F., Surace, E.M., Rossi, S., Lyubarsky, A., Arruda, V.R., Konkle, B., Stone, E., Sun, J., Jacobs, J., Dell'Osso, L., Hertle, R., Ma, J., Redmond, T.M., Zhu, X., Hauck, B., Zelenaia, O., Shindler, K.S., Maguire, M.G., Wright, J.F., Volpe, N.J., McDonnell, J.W., Auricchio, A., High, K.A., Bennett, J., 2008. Safety and efficacy of gene transfer for Leber's congenital amaurosis. N Engl J Med 358, 22402248.

Marmor, M.F., Wolfensberger, T.J., 1998. The Retinal Pigment Epithelium: Function and Disease. Oxford University Press, USA.

Marmorstein, A.D., Marmorstein, L.Y., Rayborn, M., Wang, X., Hollyfield, J.G., Petrukhin, K., 2000. Bestrophin, the product of the Best vitelliform macular dystrophy gene (VMD2), localizes to the basolateral plasma membrane of the retinal pigment epithelium. Proc Natl Acad Sci USA 97, 12758-12763.

Marneros, A.G., Fan, J., Yokoyama, Y., Gerber, H.P., Ferrara, N., Crouch, R.K., Olsen, B.R., 2005. Vascular endothelial growth factor expression in the retinal pigment epithelium is essential for choriocapillaris development and visual function. Am $\mathrm{J}$ Pathol 167, 1451-1459. 
Marquardt, A., Stöhr, H., Passmore, L.A., Krämer, F., Rivera, A., Weber, B.H., 1998. Mutations in a novel gene, VMD2, encoding a protein of unknown properties cause juvenile-onset vitelliform macular dystrophy (Best's disease). Hum Mol Genet 7, $1517-1525$.

McAllister, J.T., Dubis, A.M., Tait, D.M., Ostler, S., Rha, J., Stepien, K.E., Summers, C.G., Carroll, J., 2010. Arrested development: high-resolution imaging of foveal morphology in albinism. Vis. Res 50, 810-817.

McKay, B.S., Burke, J.M., 1994. Separation of phenotypically distinct subpopulations of cultured human retinal pigment epithelial cells. Exp Cell Res 213, 85-92.

Miller, S.S., Edelman, J.L., 1990. Active ion transport pathways in the bovine retinal pigment epithelium. J Physiol 424, 283-300.

Moe, M.C., Kolberg, R.S., Sandberg, C., Vik-mo, E., Olstorn, H., Varghese, M., Langmoen, I.A., Nicolaissen, B., 2009. A comparison of epithelial and neural properties in progenitor cells derived from the adult human ciliary body and brain. Exp Eye Res 88, 30-38.

Mohan, N., Monickaraj, F., Balasubramanyam, M., Rema, M., Mohan, V., 2012. Imbalanced levels of angiogenic and angiostatic factors in vitreous, plasma and postmortem retinal tissue of patients with proliferative diabetic retinopathy. $\mathrm{J}$ Diabetes Complicat. 26, 435-441.

Moiseyev, G., Chen, Y., Takahashi, Y., Wu, B.X., Ma, J.-X., 2005. RPE65 is the isomerohydrolase in the retinoid visual cycle. Proc Natl Acad Sci USA 102, 1241312418. 
Murphy-Erdosh, C., Napolitano, E.W., Reichardt, L.F., 1994. The expression of B-cadherin during embryonic chick development. Dev Biol 161, 107-125.

Nabi, I.R., Mathews, A.P., Cohen-Gould, L., Gundersen, D., Rodriguez-Boulan, E., 1993. Immortalization of polarized rat retinal pigment epithelium. J Cell Sci 104, 37-49.

Nakazawa, M., Ohguro, H., Takeuchi, K., Miyagawa, Y., Ito, T., Metoki, T., 2011. Effect of nilvadipine on central visual field in retinitis pigmentosa: a 30-month clinical trial. Ophthalmologica 225, 120-126.

Nandrot, E.F., Anand, M., Almeida, D., Atabai, K., Sheppard, D., Finnemann, S.C., 2007. Essential role for MFG-E8 as ligand for alphavbeta5 integrin in diurnal retinal phagocytosis. Proc Natl Acad Sci USA 104, 12005-12010.

Nandrot, E.F., Finnemann, S.C., 2006. Altered rhythm of photoreceptor outer segment phagocytosis in beta5 integrin knockout mice. Adv Exp Med Biol 572, 119-123.

Nandrot, E.F., Kim, Y., Brodie, S.E., Huang, X., Sheppard, D., Finnemann, S.C., 2004. Loss of synchronized retinal phagocytosis and age-related blindness in mice lacking alphavbeta5 integrin. J Exp Med 200, 1539-1545.

Newton, J.M., Cohen-Barak, O., Hagiwara, N., Gardner, J.M., Davisson, M.T., King, R.A., Brilliant, M.H., 2001. Mutations in the human orthologue of the mouse underwhite gene (uw) underlie a new form of oculocutaneous albinism, OCA4. Am J Hum Genet $69,981-988$.

Oetting, W.S., King, R.A., 1994. Analysis of tyrosinase mutations associated with tyrosinase-related oculocutaneous albinism (OCA1). Pigm Cell Res 7, 285-290. 
Ogata, N., Matsuoka, M., Imaizumi, M., Arichi, M., Matsumura, M., 2004. Decreased levels of pigment epithelium-derived factor in eyes with neuroretinal dystrophic diseases. Am J Ophthalmol 137, 1129-1130.

Ogata, N., Nishikawa, M., Nishimura, T., Mitsuma, Y., Matsumura, M., 2002. Unbalanced vitreous levels of pigment epithelium-derived factor and vascular endothelial growth factor in diabetic retinopathy. Am J Ophthalmol 134, 348-353.

Okajima, T.I., Pepperberg, D.R., Ripps, H., Wiggert, B., Chader, G.J., 1989. Interphotoreceptor retinoid-binding protein: role in delivery of retinol to the pigment epithelium. Exp Eye Res 49, 629-644.

Ong, J.M., da Cruz, L., 2012. A review and update on the current status of stem cell therapy and the retina. Br Med Bull 102, 133-146.

Osakada, F., Ikeda, H., Mandai, M., Wataya, T., Watanabe, K., Yoshimura, N., Akaike, A., Sasai, Y., Takahashi, M., 2008. Toward the generation of rod and cone photoreceptors from mouse, monkey and human embryonic stem cells. Nat Biotechnol 26, 215-224.

Osakada, F., Jin, Z.-B., Hirami, Y., Ikeda, H., Danjyo, T., Watanabe, K., Sasai, Y., Takahashi, M., 2009. In vitro differentiation of retinal cells from human pluripotent stem cells by small-molecule induction. J Cell Sci 122, 3169-3179.

Owaribe, K., Masuda, H., 1982. Isolation and characterization of circumferential microfilament bundles from retinal pigmented epithelial cells. J Cell Biol 95, 310-315.

Petrukhin, K., Koisti, M.J., Bakall, B., Li, W., Xie, G., Marknell, T., Sandgren, O., Forsman, K., Holmgren, G., Andreasson, S., Vujic, M., Bergen, A.A., McGarty-Dugan, V., 
Figueroa, D., Austin, C.P., Metzker, M.L., Caskey, C.T., Wadelius, C., 1998.

Identification of the gene responsible for Best macular dystrophy. Nat Genet 19, 241247.

Pfeffer, B.A., Clark, V.M., Flannery, J.G., Bok, D., 1986. Membrane receptors for retinolbinding protein in cultured human retinal pigment epithelium. Invest Ophthalmol Vis Sci 27, 1031-1040.

Picard, E., Houssier, M., Bujold, K., Sapieha, P., Lubell, W., Dorfman, A., Racine, J., Hardy, P., Febbraio, M., Lachapelle, P., Ong, H., Sennlaub, F., Chemtob, S., 2010. CD36 plays an important role in the clearance of oxLDL and associated agedependent sub-retinal deposits. Aging (Albany. NY). 2, 981-989.

Pinilla, I., Cuenca, N., Sauvé, Y., Wang, S., Lund, R.D., 2007. Preservation of outer retina and its synaptic connectivity following subretinal injections of human RPE cells in the Royal College of Surgeons rat. Exp Eye Res 85, 381-392.

Punzo, C., Kornacker, K., Cepko, C.L., 2009. Stimulation of the insulin/mTOR pathway delays cone death in a mouse model of retinitis pigmentosa. Nat Neurosci $12,44-52$.

Qu, Z., Hartzell, H.C., 2008. Bestrophin Cl- channels are highly permeable to HCO3-. Am J Physiol Cell Physiol 294, C1371-C1377.

Rachel, R.A., Mason, C.A., Beermann, F., 2002. Influence of tyrosinase levels on pigment accumulation in the retinal pigment epithelium and on the uncrossed retinal projection. Pigm Cell Res 15, 273-281. 
Rakoczy, P.E., Lai, C.M., Baines, M., Di Grandi, S., Fitton, J.H., Constable, I.J., 1997. Modulation of cathepsin D activity in retinal pigment epithelial cells. Biochem $\mathrm{J} 324$, 935-940.

Ramsden, C.M., Powner, M.B., Carr, A.-J.F., Smart, M.J.K., da Cruz, L., Coffey, P.J., 2013. Stem cells in retinal regeneration: past, present and future. Development 140, $2576-2585$.

Raposo, G., Marks, M.S., 2007. Melanosomes--dark organelles enlighten endosomal membrane transport. Nat Rev Mol Cell Biol 8, 786-797.

Rebsam, A., Bhansali, P., Mason, C.A., 2012. Eye-specific projections of retinogeniculate axons are altered in albino mice. J Neurosci 32, 4821-4826.

Redmond, T.M., Poliakov, E., Yu, S., Tsai, J.-Y., Lu, Z., Gentleman, S., 2005. Mutation of key residues of RPE65 abolishes its enzymatic role as isomerohydrolase in the visual cycle. Proc Natl Acad Sci USA 102, 13658-13663.

Ribeiro, R.M., Oregon, A., Diniz, B., Fernandes, R.B., Koss, M.J., Charafeddin, W., Hu, Y., Thomas, P., Thomas, B.B., Maia, M., Chader, G.J., Hinton, D.R., Humayun, M.S., 2013. In vivo detection of hESC-RPE cells via confocal near-infrared fundus reflectance. Ophthalmic Surg Lasers Imaging Retin. 44, 380-384.

Ritter, M., Zotter, S., Schmidt, W.M., Bittner, R.E., Deak, G.G., Pircher, M., Sacu, S., Hitzenberger, C.K., Schmidt-Erfurth, U.M., 2013. Characterization of stargardt disease using polarization-sensitive optical coherence tomography and fundus autofluorescence imaging. Invest Ophthalmol Vis Sci 54, 6416-6425. 
Ruiz, A., Winston, A., Lim, Y.H., Gilbert, B.A., Rando, R.R., Bok, D., 1999. Molecular and biochemical characterization of lecithin retinol acyltransferase. J Biol Chem 274, 3834-3841.

Ryeom, S.W., Silverstein, R.L., Scotto, A., Sparrow, J.R., 1996. Binding of anionic phospholipids to retinal pigment epithelium may be mediated by the scavenger receptor CD36. J Biol Chem 271, 20536-20539.

Saari, J.C., Bredberg, D.L., Farrell, D.F., 1993. Retinol esterification in bovine retinal pigment epithelium: reversibility of lecithin:retinol acyltransferase. Biochem J 291, $697-700$.

Saari, J.C., Bredberg, L., Garwin, G.G., 1982. Identification of the endogenous retinoids associated with three cellular retinoid-binding proteins from bovine retina and retinal pigment epithelium. J Biol Chem 257, 13329-13333.

Saint-Geniez, M., Kurihara, T., Sekiyama, E., Maldonado, A.E., D’Amore, P.A., 2009. An essential role for RPE-derived soluble VEGF in the maintenance of the choriocapillaris. Proc Natl Acad Sci USA 106, 18751-18756.

Salero, E., Blenkinsop, T.A., Corneo, B., Harris, A., Rabin, D., Stern, J.H., Temple, S., 2012. Adult Human RPE Can Be Activated into a Multipotent Stem Cell that Produces Mesenchymal Derivatives. Cell Stem Cell 10, 88-95.

Sancho-Pelluz, J., Arango-Gonzalez, B., Kustermann, S., Romero, F.J., van Veen, T., Zrenner, E., Ekström, P., Paquet-Durand, F., 2008. Photoreceptor cell death mechanisms in inherited retinal degeneration. Mol Neurobiol 38, 253-269. 
Schraermeyer, U., Heimann, K., 1999. Current understanding on the role of retinal pigment epithelium and its pigmentation. Pigm Cell Res 12, 219-236.

Schwartz, S.D., Hubschman, J.-P., Heilwell, G., Franco-Cardenas, V., Pan, C.K., Ostrick, R.M., Mickunas, E., Gay, R., Klimanskaya, I., Lanza, R., 2012. Embryonic stem cell trials for macular degeneration: a preliminary report. Lancet 379, 713-720.

Sheridan, C., Williams, R., Grierson, I., 2004. Basement membranes and artificial substrates in cell transplantation. Graefes Arch Clin Exp Ophthalmol 242, 68-75.

Sieving, P.A., Caruso, R.C., Tao, W., Coleman, H.R., Thompson, D.J.S., Fullmer, K.R., Bush, R.A., 2006. Ciliary neurotrophic factor (CNTF) for human retinal degeneration: Phase I trial of CNTF delivered by encapsulated cell intraocular implants. Proc Natl Acad Sci USA 103, 3896-3901.

Simon, A., Hellman, U., Wernstedt, C., Eriksson, U., 1995. The retinal pigment epithelialspecific 11 -cis retinol dehydrogenase belongs to the family of short chain alcohol dehydrogenases. J Biol Chem 270, 1107-1112.

Skaf, A.R., Mahmoud, T., 2011. Surgical treatment of age-related macular degeneration. Semin Ophthalmol 26, 181-191.

Smith, A.J., Bainbridge, J.W., Ali, R.R., 2009. Prospects for retinal gene replacement therapy. Trends Genet 25, 156-165.

Stamer, W.D., Bok, D., Hu, J., Jaffe, G.J., McKay, B.S., 2003. Aquaporin-1 Channels in Human Retinal Pigment Epithelium: Role in Transepithelial Water Movement. Invest Ophthalmol Vis Sci 44, 2803-2808. 
Stanton, J.B., Goldberg, A.F.X., Hoppe, G., Marmorstein, L.Y., Marmorstein, A.D., 2006. Hydrodynamic properties of porcine bestrophin-1 in Triton X-100. Biochim Biophys Acta 1758, 241-247.

Stanzel, B. V., Liu, Z., Somboonthanakij, S., Wongsawad, W., Brinken, R., Eter, N., Corneo, B., Holz, F.G., Temple, S., Stern, J.H., Blenkinsop, T.A., 2014. Human RPE Stem Cells Grown into Polarized RPE Monolayers on a Polyester Matrix Are Maintained after Grafting into Rabbit Subretinal Space. Stem Cell Rep 2, 64-77.

Steinmetz, R.L., Garner, A., Maguire, J.I., Bird, A.C., 1991. Histopathology of incipient fundus flavimaculatus. Ophthalmology 98, 953-956.

Strauss, O., 2005. The Retinal Pigment Epithelium in Visual Function. Physiol Rev 85, 845-881.

Strauss, O., Müller, C., Reichhart, N., Tamm, E.R., Gomez, N.M., 2014. The role of bestrophin-1 in intracellular ca(2+) signaling. Adv Exp Med Biol 801, 113-119.

Sullivan, J.M., 2009. Focus on molecules: ABCA4 (ABCR)--an import-directed photoreceptor retinoid flipase. Exp Eye Res 89, 602-603.

Summers, C.G., 2009. Albinism: classification, clinical characteristics, and recent findings. Optom Vis Sci 86, 659-662.

Sun, H., Tsunenari, T., Yau, K.-W., Nathans, J., 2002. The vitelliform macular dystrophy protein defines a new family of chloride channels. Proc Natl Acad Sci USA 99, 40084013. 
Sun, M., Finnemann, S.C., Febbraio, M., Shan, L., Annangudi, S.P., Podrez, E.A., Hoppe, G., Darrow, R., Organisciak, D.T., Salomon, R.G., Silverstein, R.L., Hazen, S.L., 2006. Light-induced oxidation of photoreceptor outer segment phospholipids generates ligands for CD36-mediated phagocytosis by retinal pigment epithelium: a potential mechanism for modulating outer segment phagocytosis under oxidant stress conditions. J Biol Chem 281, 4222-4230.

Surace, E.M., Angeletti, B., Ballabio, A., Marigo, V., 2000. Expression pattern of the ocular albinism type 1 (Oa1) gene in the murine retinal pigment epithelium. Invest Ophthalmol Vis Sci 41, 4333-4337.

Takahashi, K., Yamanaka, S., 2006. Induction of pluripotent stem cells from mouse embryonic and adult fibroblast cultures by defined factors. Cell 126, 663-676.

Tezel, T.H., Del Priore, L. V, Berger, A.S., Kaplan, H.J., 2007. Adult retinal pigment epithelial transplantation in exudative age-related macular degeneration. Am J Ophthalmol 143, 584-595.

Tropepe, V., Coles, B.L.K., Chiasson, B.J., Horsford, D.J., Elia, A.J., McInnes, R.R., van der Kooy, D., 2000. Retinal stem cells in the adult mammalian eye. Science (80-. ). 287, 2032-2036.

Ugarte, M., Osborne, N.N., 2014. Recent advances in the understanding of the role of zinc in ocular tissues. Metallomics 6, 189-200.

Van Meurs, J.C., Van Den Biesen, P.R., 2003. Autologous retinal pigment epithelium and choroid translocation in patients with exudative age-related macular degeneration: short-term follow-up. Am J Ophthalmol 136, 688-695. 
Vollrath, D., Feng, W., Duncan, J.L., Yasumura, D., D’Cruz, P.M., Chappelow, A., Matthes, M.T., Kay, M.A., LaVail, M.M., 2001. Correction of the retinal dystrophy phenotype of the RCS rat by viral gene transfer of Mertk. Proc Natl Acad Sci USA 98, 1258412589.

Vossmerbaeumer, U., Kuehl, S., Kern, S., Kluter, H., Jonas, J.B., Bieback, K., 2008. Induction of retinal pigment epithelium properties in ciliary margin progenitor cells. Clin Exp. Ophthalmol 36, 358-366.

Wang, Y., Subramanian, P., Shen, D., Tuo, J., Becerra, S.P., Chan, C.-C., 2013. Pigment epithelium-derived factor reduces apoptosis and pro-inflammatory cytokine gene expression in a murine model of focal retinal degeneration. ASN Neuro 5, 309-319.

Weng, T.X., Godley, B.F., Jin, G.F., Mangini, N.J., Kennedy, B.G., Yu, A.S.L., Wills, N.K., 2002. Oxidant and antioxidant modulation of chloride channels expressed in human retinal pigment epithelium. Am J Physiol Cell Physiol 283, C839-849.

West, E.L., Pearson, R.A., Barker, S.E., Luhmann, U.F.O., MacLaren, R.E., Barber, A.C., Duran, Y., Smith, A.J., Sowden, J.C., Ali, R.R., 2010. Long-term survival of photoreceptors transplanted into the adult murine neural retina requires immune modulation. Stem Cells 28, 1997-2007.

West, E.L., Pearson, R.A., Duran, Y., MacLaren, R.E., Smith, A.J., Sowden, J.C., Ali, R.R., 2012. Manipulation of the Recipient Retinal Environment by Ectopic Expression of Neurotrophic Growth Factors Can Improve Transplanted Photoreceptor Integration and Survival. Cell Trannsplant 21, 871-887. 
Williams, C.D., Rizzolo, L.J., 1997. Remodeling of junctional complexes during the development of the outer blood-retinal barrier. Anat Rec 249, 380-388.

Wright, A.F., Chakarova, C.F., Abd El-Aziz, M.M., Bhattacharya, S.S., 2010. Photoreceptor degeneration: genetic and mechanistic dissection of a complex trait. Nat Rev Genet $11,273-284$.

Young, R.W., Bok, D., 1969. Participation of the retinal pigment epithelium in the rod outer segment renewal process. J Cell Biol 42, 392-403.

Zahabi, A., Shahbazi, E., Ahmadieh, H., Hassani, S.-N., Totonchi, M., Taei, A., Masoudi, N., Ebrahimi, M., Aghdami, N., Seifinejad, A., Mehrnejad, F., Daftarian, N., Salekdeh, G.H., Baharvand, H., 2012. A new efficient protocol for directed differentiation of retinal pigmented epithelial cells from normal and retinal disease induced pluripotent stem cells. Stem Cells Dev 21, 2262-2272.

Zrenner, E., 2002. Will retinal implants restore vision? Science (80-. ). 295, 1022-1025.

Zrenner, E., Bartz-Schmidt, K.U., Benav, H., Besch, D., Bruckmann, A., Gabel, V.-P., Gekeler, F., Greppmaier, U., Harscher, A., Kibbel, S., Koch, J., Kusnyerik, A., Peters, T., Stingl, K., Sachs, H., Stett, A., Szurman, P., Wilhelm, B., Wilke, R., 2011. Subretinal electronic chips allow blind patients to read letters and combine them to words. Proc Biol Sci 278, 1489-1497. 


\section{Figure legends}

Figure 1. Schematic representation of RPE cells and their polarized phenotype.

RPE cells show asymmetric distribution of proteins in apical and basolateral membrane domains. The apical membrane is characterized by microvilli and is separated from the basolateral membrane by tight junctions. Actin filaments form the circumferential microfilament bundles that attach to the zonula adherens. Gap junctions mediate communication between RPE cells. The basal membrane is characterized by infoldings and attaches to its basal lamina and to the Bruch's membrane. Melanosomes are represented with black round and oval shapes and mitochondria with ellipsoidal shapes below the nuclei.

Figure 2. RPE functions.

(A) POS phagocytosis requires receptors on the RPE surface. POS are bound by $\alpha \mathrm{v} \beta 5$ integrin and the scavenger receptor CD36 mediates POS uptake by RPE. Internalization of POS requires MERTK that is activated through phosphorylation by FAK. One of the receptors for MERTK is GAS6. (B) Visual cycle is initiated by the hit of rhodopsin by a photon that causes isomerisation of 11-cis-retinal into all-trans-retinal. In the photoreceptor outer segment all-trans retinal is exposed to the cytoplasmic membrane surface by ABCA4 and reduced to all-trans retinol by $\mathrm{RDH}$. all-trans retinol is transported to the RPE by IRBP and delivered to CRALBP. RPE can receive all-trans retinol also from the choroidal vasculature through interaction between the retinol carrier RBP/TTR complex and the STRA6 receptor. The conversion of all-trans retinol to 11-cis retinal requires an enzymatic cascade involving LRAT, RPE65 and RDH5. 11-cis retinal then exits the RPE bound to IRBP and reconstitutes rhodopsin. (C) Transport mechanisms in the RPE require $\mathrm{Na}^{+} / \mathrm{K}^{+}$ ATPase and, among several ion channels, $\mathrm{Na}^{+}-\mathrm{K}^{+}-2 \mathrm{Cl}^{-}$and $\mathrm{HCO}_{3} / \mathrm{Na}^{+}$co-transporters at 
the apical membrane. The basolateral membrane hosts $\mathrm{K}^{+}$channels and $\mathrm{Cl}^{-}$channels (CFTR and bestrophin 1). $\mathrm{H}_{2} \mathrm{O}$ transport is mediated by aquaporins. PEDF is secreted at the apical side and VEGF-A from the basal side. (D) Melanosomes develop through sequential maturation stages. Stage I premelanosomes (st.I) correspond to early endosomal vacuoles in which Pmel17 organizes into amyloid-like fibrillar structures, visible in stage II unpigmented melanosomes (st.II). Melanogenetic enzymes are transferred to the maturing organelles. The deposition of black melanin along the fibers is initiated in stage III melanosomes (st.III). Mature stage IV melanosomes (st.IV) are fully pigmented.

Figure 3. Proliferation analyses in retinal neurospheres (RNS) derived from human ciliary bodies and in cells differentiated into RPE.

(A-C) Phase-contrast images and (D-F) BrdU immunostaining of pigmented RNS after 3 (A, D), $7(B, E)$ and $9(C, F)$ days in culture. Proliferation declined with time in culture when assessed by BrdU labeling (antibody used 1:8000, Developmental Hybridoma, red, arrows). Nuclei were stained with 4',6-diamidino-2-phenylindole (DAPI, blue in D-F). (G-L) RNS cells were dissociated and seeded on ECM for differentiation into a RPE monolayer and analyzed after 7 days (G-H), 14 days (I-J) and 21 days (K-L) of differentiation in vitro. Phase-contrast images show the morphology of cells (G, I, K) and immunofluorescence images of the same fields show BrdU labeling (red staining in $H, J, L$ ). Proliferation was not observed in more pigmented and thus more differentiated cells (see insert in panel G, where the black arrow indicates BrdU negative cells and red arrows indicate BrdU positive cells). (M) Graph with the percentages and standard deviations of proliferating cells at different times during RPE differentiation in vitro. $d=$ days in culture. Scale bars $(100 \mu \mathrm{m})$ are shown in the immunofluorescence images. 


\section{Figure 4. Epithelial features of the in vitro differentiated RPE layer.}

Immunofluorescence analysis of RPE markers (red) in differentiated RPE-like cells after 7 days $(A, D, G, J, M, R)$ and 21 days $(B, E, H, K, N)$ of culture and in the MDCK cell line $(C$, F, I, L, O). Nuclei were stained with DAPI (blue). Epithelial tight-junction protein ZO-1 (antibody used 1:100, Invitrogen) showed membrane localization in 21 days differentiated RPE cells and in MDCK cells (B-C) but not in cells after 7 days in culture (A). Polarization of the newly formed epithelium was analyzed by confocal microscopy. $\beta 5$-integrin (antibody used 1:20, Abcam) was detected in RPE cells at 7 and 21 days of differentiation $(\mathrm{D}-\mathrm{E})$ and in MDCK cells $(\mathrm{F})$; below $\mathrm{D}, \mathrm{E}, \mathrm{F}$ the $\mathrm{z}$-axes images show that $\beta 5$-integrin localizes apically in RPE cells (arrows) above the nuclei stained in blue. Apical localization of ezrin (antibody used 1:250, Sigma) was detected in RPE cells at 7 and 21 days of differentiation (G-H) as well as in MDCK cells (I); below $\mathrm{G}, \mathrm{H}, \mathrm{I}$ the z-axes images confirm that ezrin localizes apically above the nuclei stained in blue. Basolateral localization of bestrophin 1 (antibody used 1:1000, Novus Biologicals) was detected in RPE cells at 7 and 21 days of differentiation (J-K) but not in MDCK cells (L); below J, K, L the z-axes images confirm that bestrophin 1 localizes basolaterally in RPE differentiated cells (arrows) beneath the nuclei stained in blue. Expression of LRAT (antibody used 1:100, kindly provided by Dr. K. Palczewski) was detected in RPE cells at 7 and 21 days of differentiation (M-N) but not in MDCK cells (O); below $\mathrm{M}, \mathrm{N}, \mathrm{O}$ the z-axes images confirm that LRAT localizes intracellularly in RPE cells. The negative control of immunofluorescence (R) was performed in RPE cells at 7 days of differentiation by incubation with the Alexa Fluor 568 goat anti-rabbit secondary antibody (Molecular Probes). Scale bars are: $100 \mu \mathrm{m}(\mathrm{G}-\mathrm{H}), 50 \mu \mathrm{m}(\mathrm{A}, \mathrm{B}, \mathrm{D}, \mathrm{E}, \mathrm{I}, \mathrm{M}, \mathrm{N}), 25 \mu \mathrm{m}(\mathrm{C}, \mathrm{F}, \mathrm{O}, \mathrm{R})$ and $20 \mu \mathrm{m}(\mathrm{J}, \mathrm{K}, \mathrm{L})$. 3D confocal reconstructions of cells labeled with $\beta 5$-integrin $(\mathrm{P})$ and bestrophin $1(Q)$ after 21 days of differentiation confirm apical $\beta 5$-integrin and basolateral 
bestrophin 1 localizations. $\beta 5$-integrin and bestrophin 1 are labeled in red and nuclei are shown in blue. 3D analysis was performed with the Huygens professional program.

Figure 5. Expression of RPE specific markers and phagocytosis ability of in vitro differentiated RPE.

(A) Western blot analysis of CRALBP (antibody used 1:1000, Abcam) and RPE65 (antibody used 1:1000, kindly provided by Dr. M. Redmond) in RNS, adult human RPE (ad.RPE) and in in vitro differentiated RPE at 7, 14 and 21 days. Western blots were normalized with anti-actin antibodies (1:2000, Millipore). (B) Quantification of western blots shown in A defined that CRALBP was expressed at all analyzed times and increased with time of differentiation in vitro (black bars). RPE65 was detectable in RNS and only after 21 days of differentiation (grey bars). Quantification of western blots was performed with the Image $\mathrm{J}$ software normalizing each sample to actin, and protein levels were compared to adult RPE that was set equal to 1. (C) Real time q-PCR analysis of H-MITF mRNA levels. No expression was detected in the ciliary body (CB), low expression in RNS and increased expression in differentiated cells. Expression of H-MITF was higher in in vitro differentiated RPE after 21 days of differentiation compared to adult RPE. (D-E) MITF protein expression was analyzed by confocal microscopy. Images are a single optical section passing through the nuclei of RPE cells immunostained with anti-MITF antibody (1:1000, Santa Cruz Biotechnology, green) after 7 (D) and 14 (E) days of differentiation. MITF co-localized with nuclear DAPI staining (blue) after 14 days in culture (E). (F-G) Real-time qPCR of PEDF $(\mathrm{F})$ and $O A 1(\mathrm{G})$ transcripts detected expression of these genes in the in vitro RPE only after 21 days of differentiation. Real-time qPCR were normalized with S26 ribosomal mRNA. (H) Phagocytosis assay: RPE cells, after differentiation in vitro for 21 days, were incubated with fluorescein labeled POS (green) for 3 hours. Cells were then labeled with 
anti-ZO-1 antibody and nuclei were stained with DAPI (blue). Confocal analysis showed no co-localization between POS (green) and ZO-1 (red). The lower panel shows the z-axis that confirms POS internalization: POS (green arrows) localized between ZO-1 labeled tight junctions (red arrows) and nuclei (blue). (I) Histogram representing number of POS per cell internalized by RPE cells after 1 and 3 hours of exposure to fluorescein labeled POS. Scale bars in D, E and $\mathrm{H}$ are $20 \mu \mathrm{m}$. 


\section{Acronyms}

ABCA4: ATP-binding cassette subfamily A member 4

AMD: Age-related Macular Degeneration

AP-1/AP-3: adaptor-protein complex 1/3

bFGF: basic fibroblast growth factor

BrdU: 5-bromo-2'-deoxyuridine

CFTR: cystic fibrosis transmembrane conductance regulator

CRALBP: cellular retinaldehyde-binding protein

DAPI: 4',6-diamidino-2-phenylindole

DMEM-F12: Dulbecco's Modified Eagle Medium-Nutrient Mixture F12

ECM: extracellular matrix from Engelbreth-Holm-Swarm murine sarcoma

ESCs: embryonic stem cells

FAK: Focal Adhesion Kinase

GAS6: growth arrest specific protein 6

iPSCs: induced pluripotent stem cells

IRBP: interphotoreceptor retinoid-binding protein

LRAT: lecithin:retinol acyltransferase

MATP: membrane-associated transport protein

MERTK: c-mer proto-oncogene tyrosine kinase

MFG-E8: milk fat globule-EGF 8

MITF: microphthalmia-associated transcription factor

MLANA: melan-A

MYO7A: myosin VIIA

OA1: ocular albinism type 1 
OSKM: OCT4 and SOX2 and KLF4 and c-MYC

OTX2: orthodenticle homolog 2

PAX6: paired box 6

PEDF: pigment epithelium-derived factor

PMEL17: premelanosomal protein 17

POS: photoreceptor cell outer segments

PVR: proliferative vitreoretinopathy

RBP/TTR: retinol-binding protein/transthyretin

$\mathrm{RDH}$ : retinol dehydrogenase

RNS: retinal neurospheres

RP: Retinitis Pigmentosa

RPE: retinal pigment epithelium

RPE65: retinal pigment epithelium-specific protein $65 \mathrm{kDa}$

RSCs: retinal stem cells

STGD: Stargardt's Disease

VEGF-A: vascular endothelial growth factor A

VMD: Vitelliform Macular Distrophy

ZO-1: zona occludens 1 


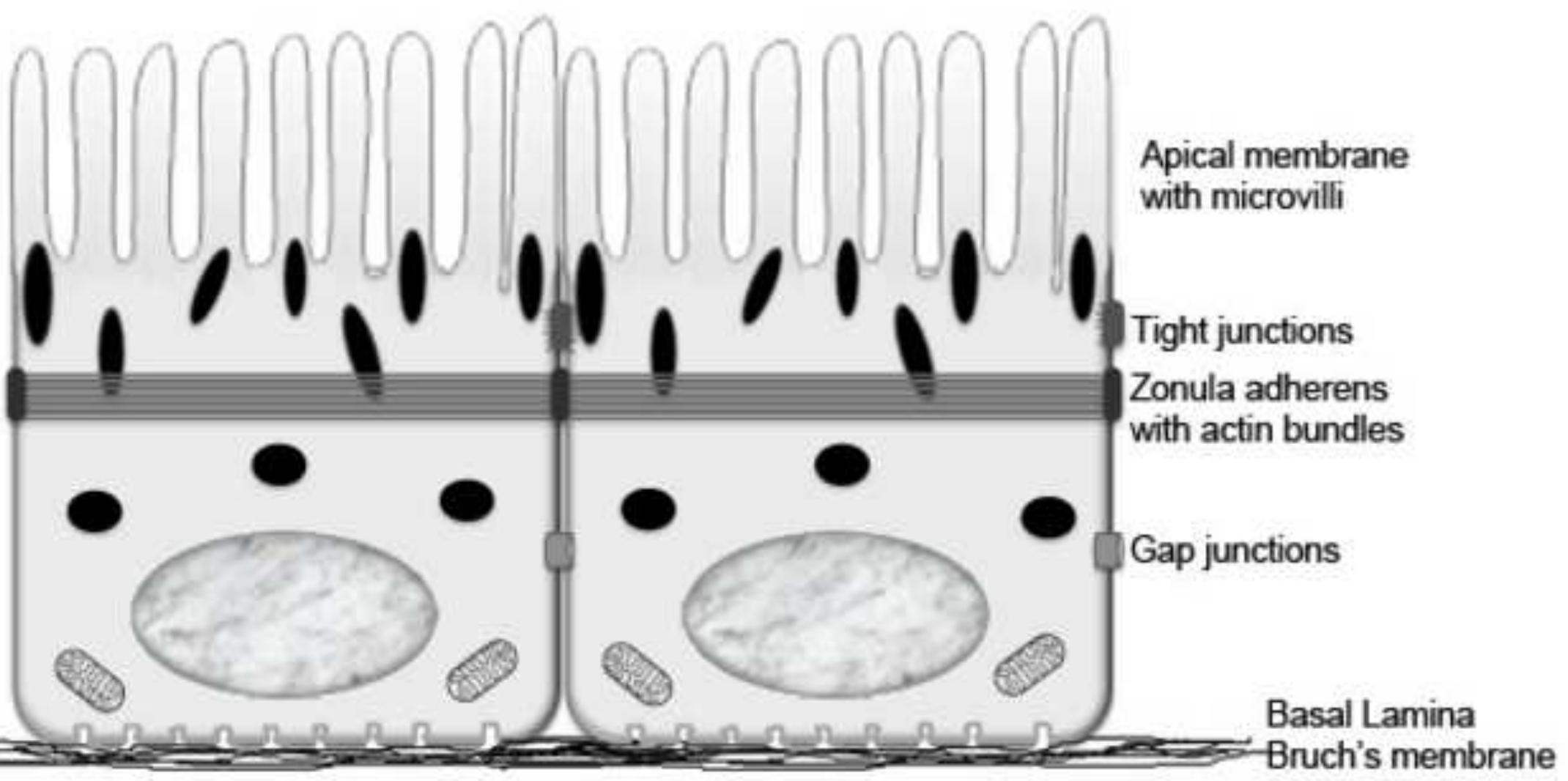



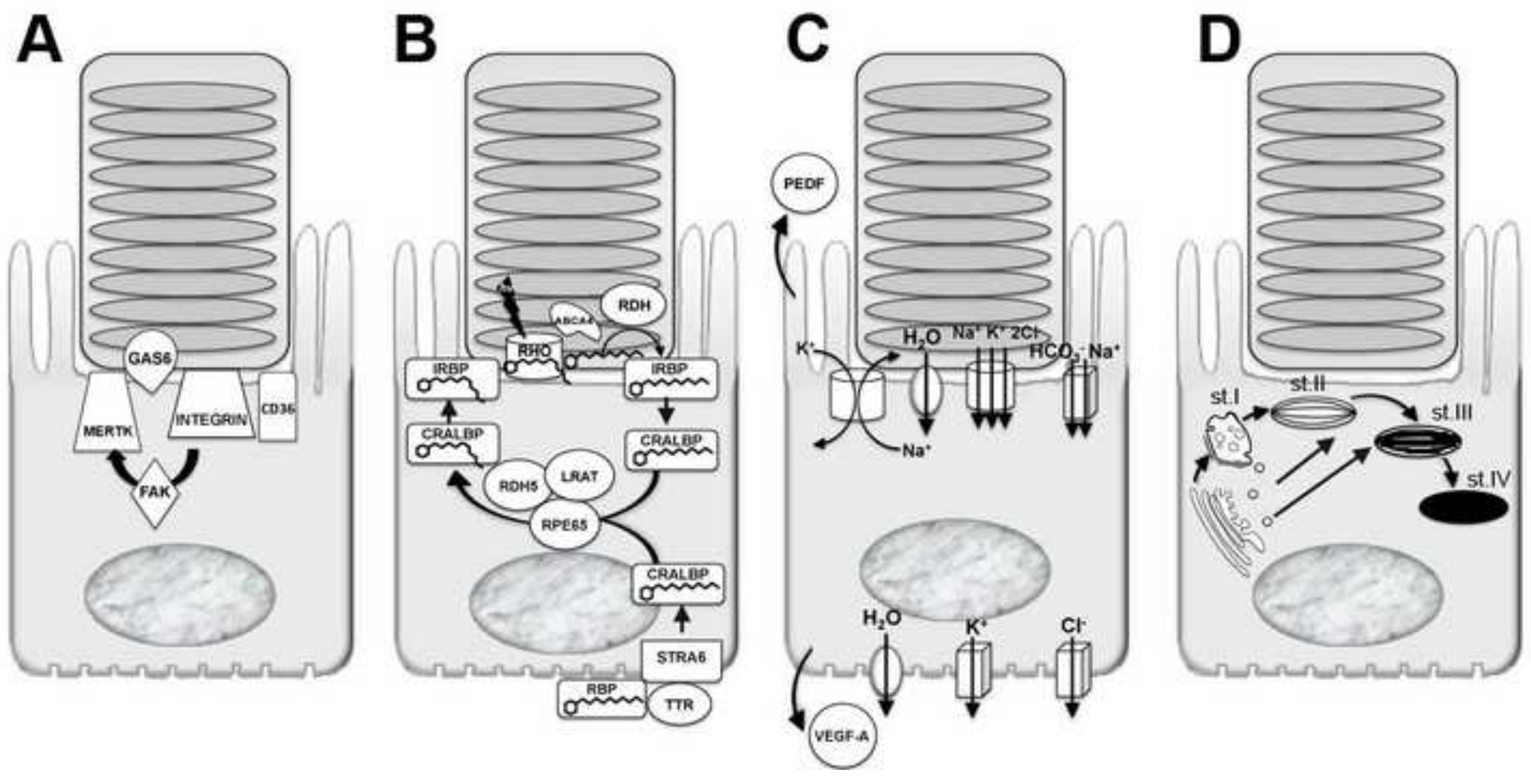
Click here to download high resolution image

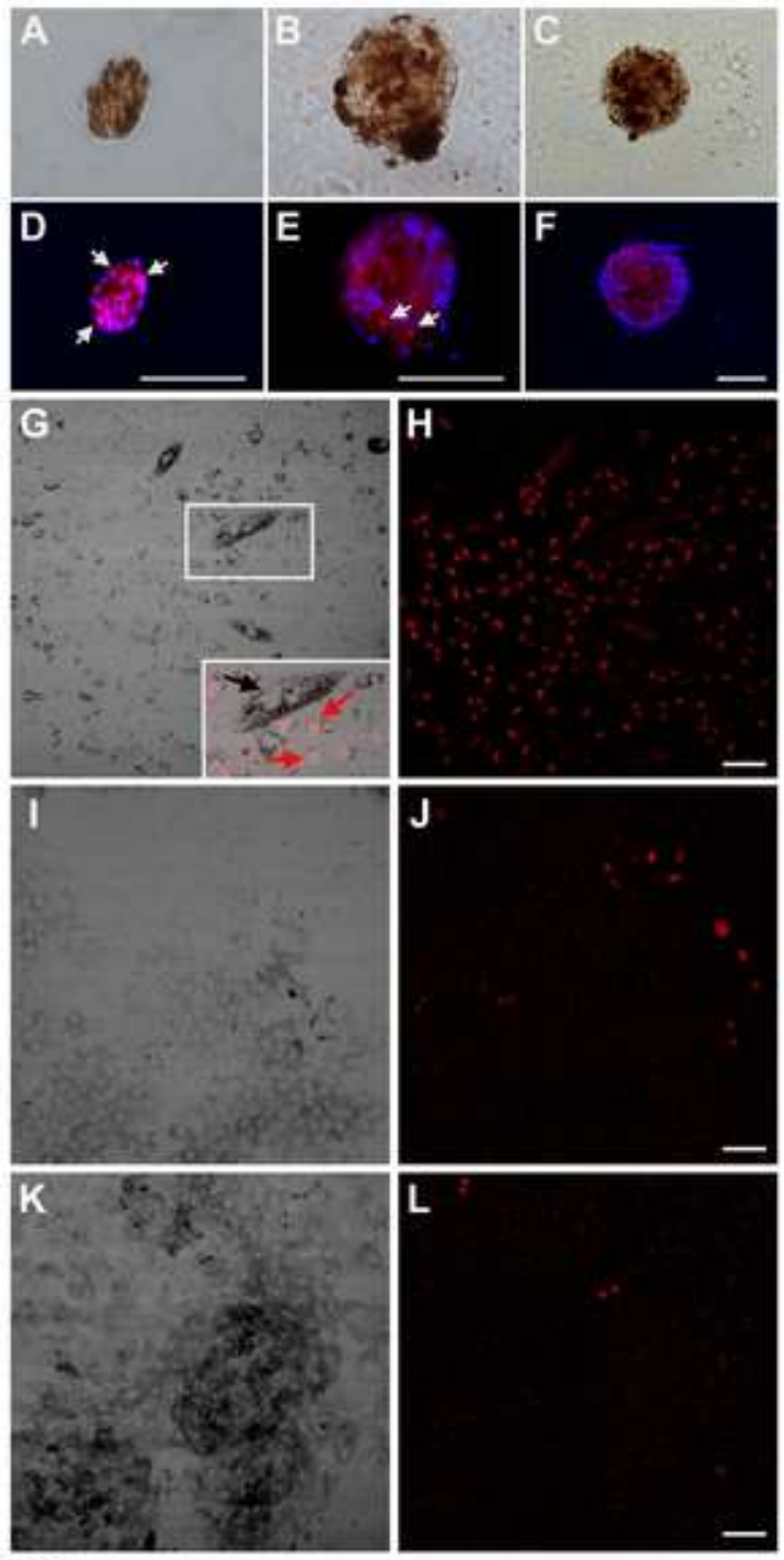

M

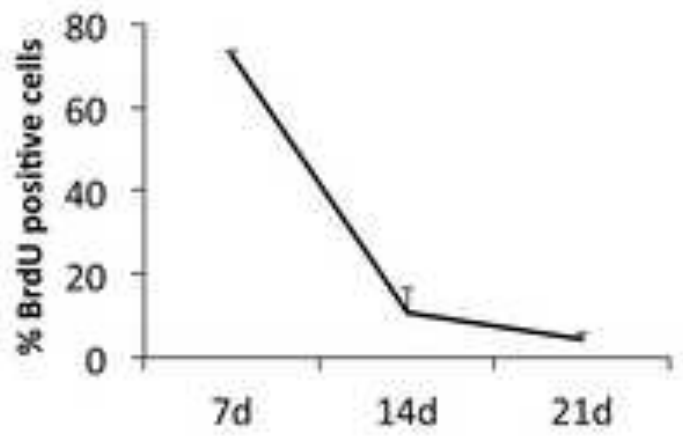




\section{Figure 4}

Click here to download high resolution image

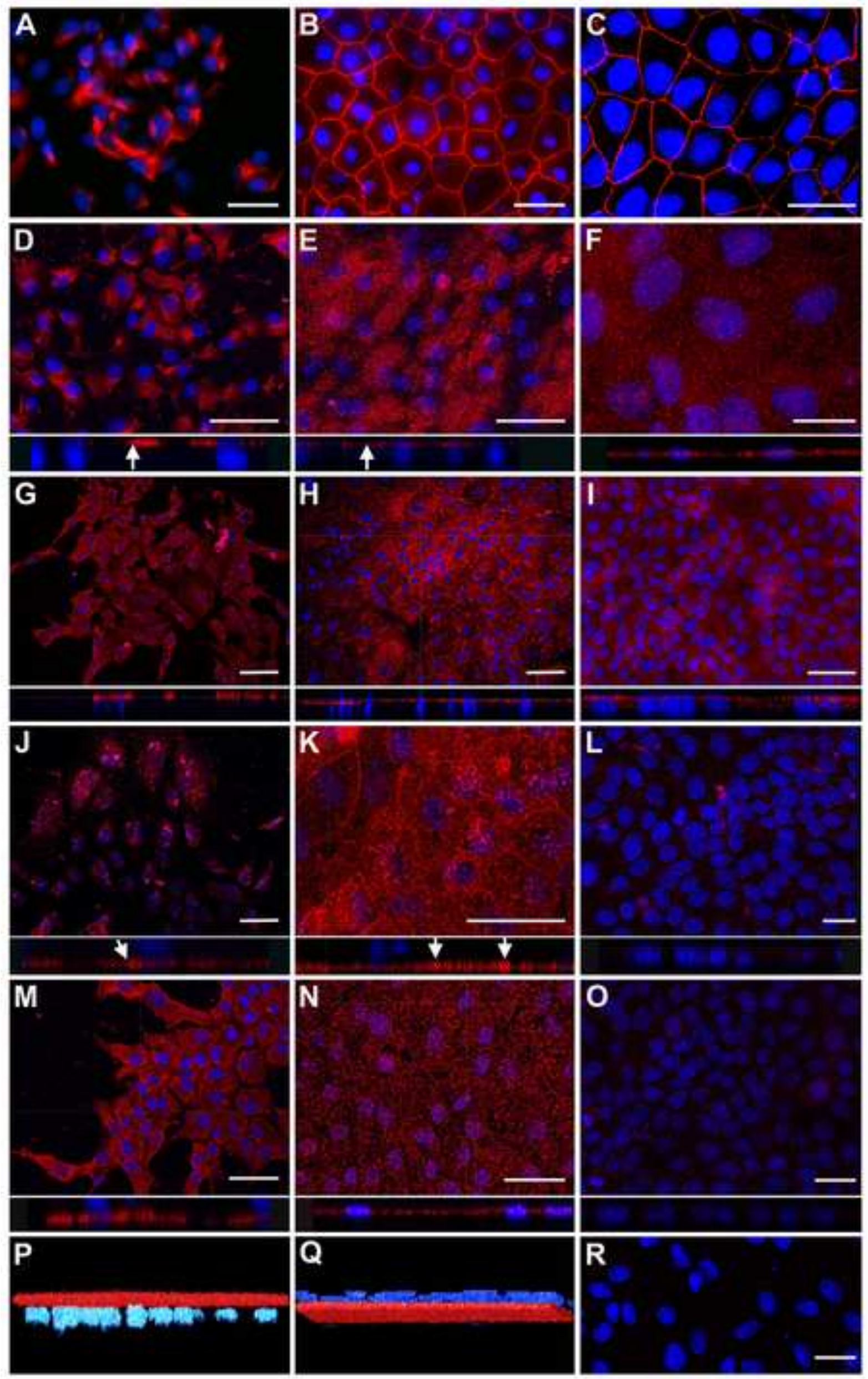


Click here to download high resolution image
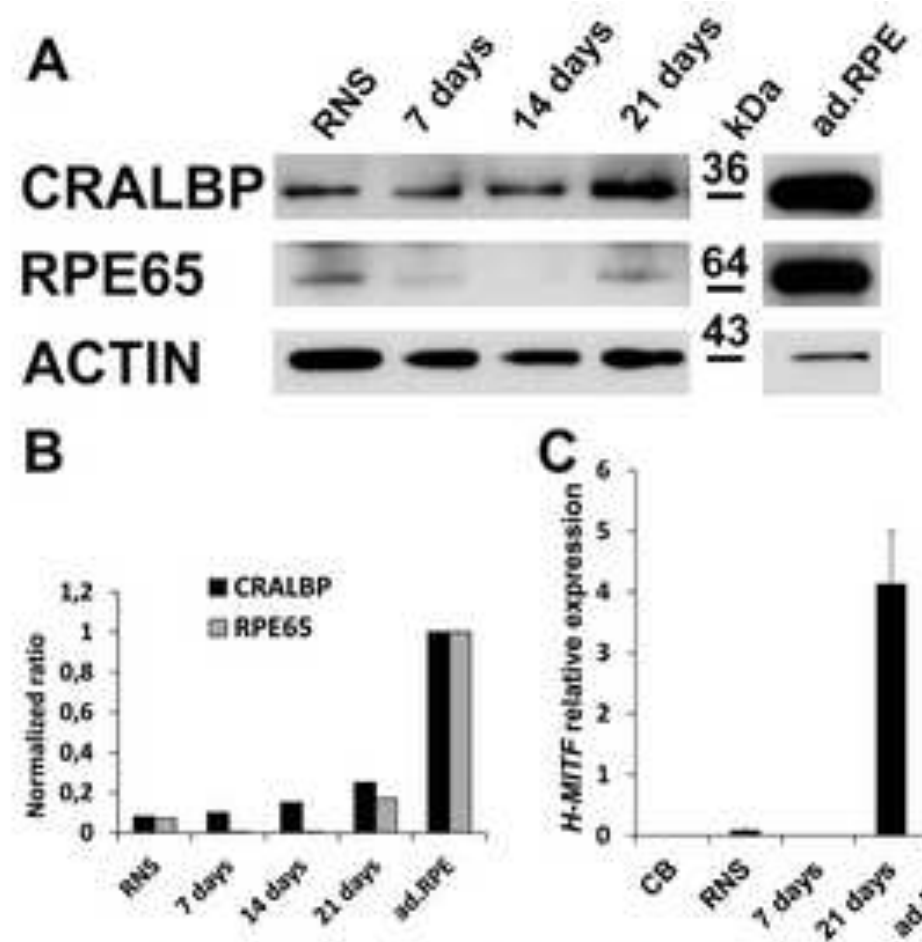

CRALBP 36

RPE65

$\underline{64}$

B
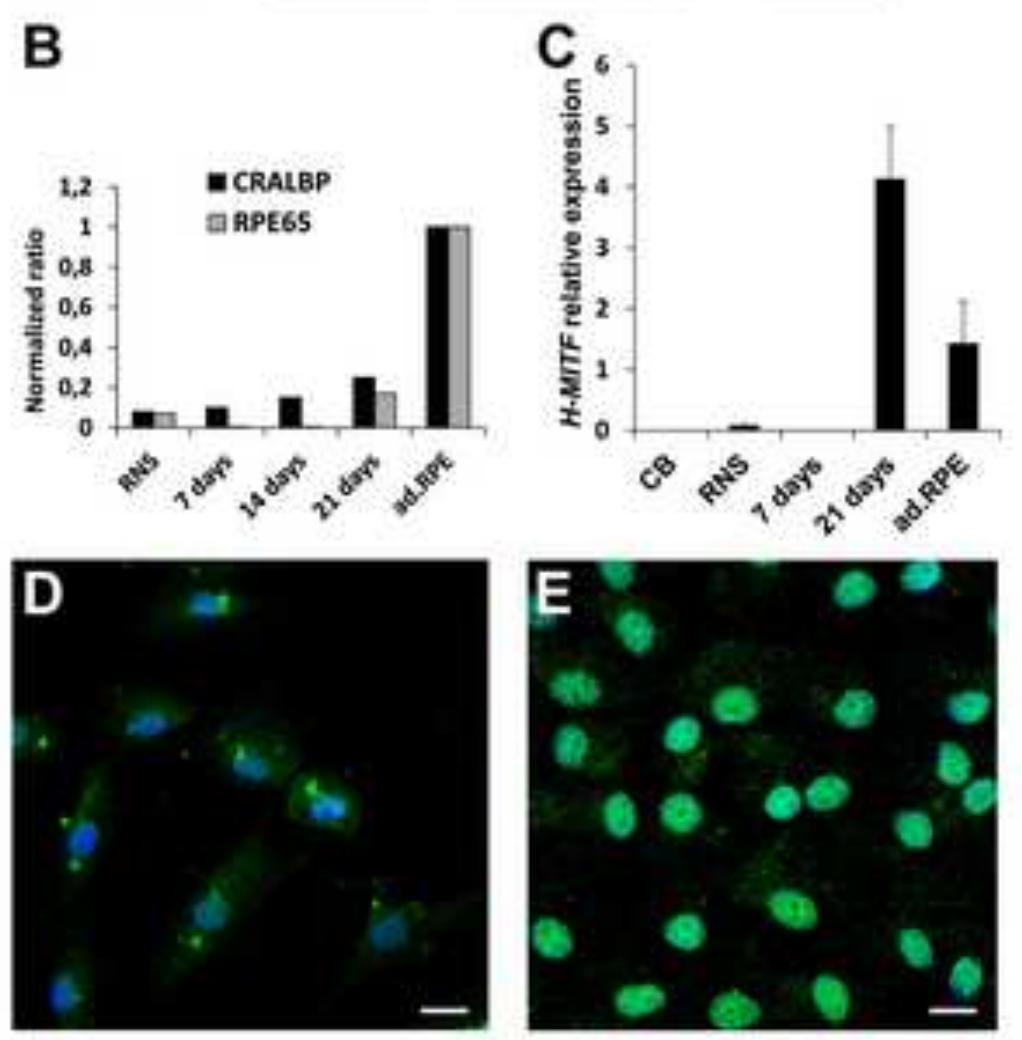

$\mathbf{F}$
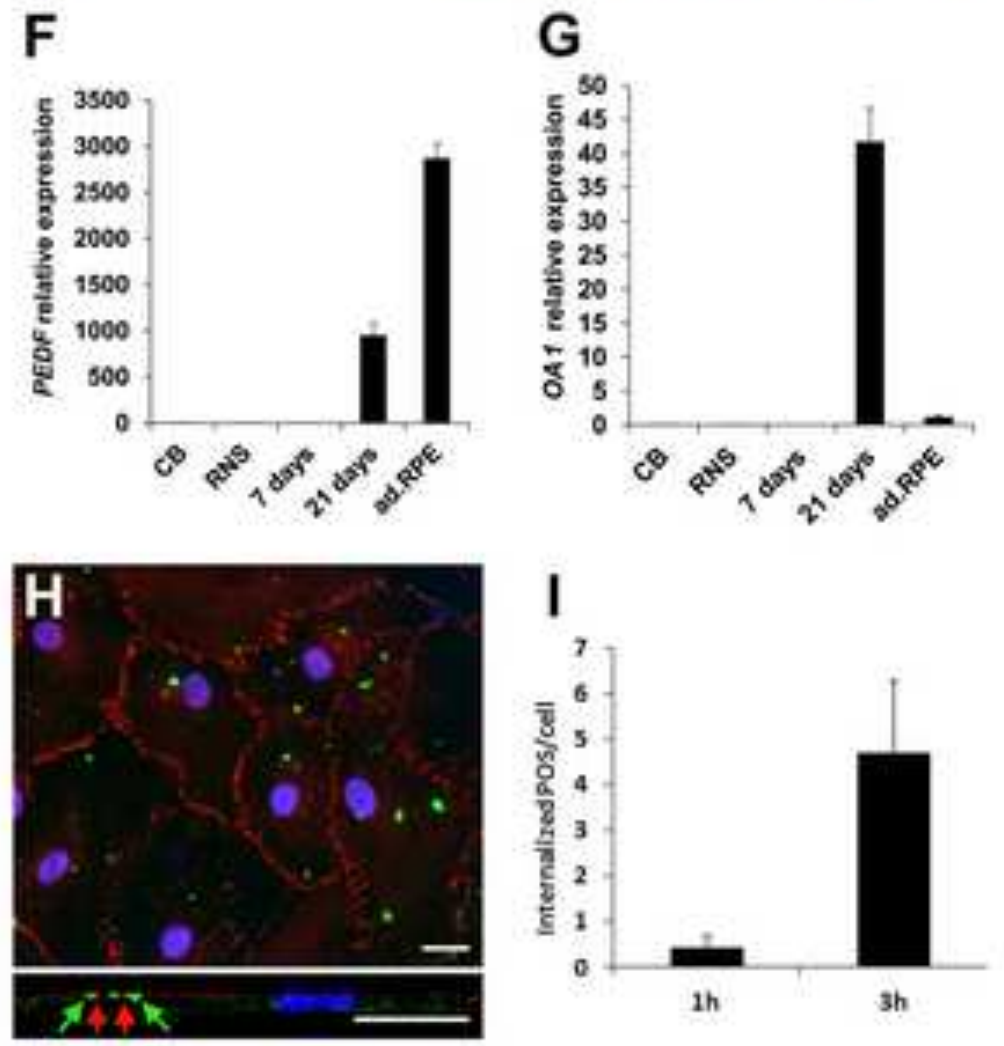